\title{
NW European shelf under climate warming: implications for open ocean - shelf exchange, primary production, and carbon absorption
}

\author{
M. Gröger ${ }^{1}$, E. Maier-Reimer ${ }^{1}$, U. Mikolajewicz ${ }^{1}$, A. Moll ${ }^{2}$, and D. Sein ${ }^{1}$ \\ ${ }^{1}$ Max Planck Institute for Meteorology, Bundesstrasse 53, 20146 Hamburg, Germany \\ ${ }^{2}$ Institut für Meereskunde, Universität Hamburg (CEN), Bundesstrasse 53, 20146 Hamburg, Germany \\ Correspondence to: M. Gröger (matthias.groeger@zmaw.de)
}

Received: 7 November 2012 - Published in Biogeosciences Discuss.: 21 November 2012

Revised: 30 April 2013 - Accepted: 3 May 2013 - Published: 12 June 2013

\begin{abstract}
Shelves have been estimated to account for more than one-fifth of the global marine primary production. It has been also conjectured that shelves strongly influence the oceanic absorption of anthropogenic $\mathrm{CO}_{2}$ (carbon shelf pump). Owing to their coarse resolution, currently applied global climate models are inappropriate to investigate the impact of climate change on shelves and regional models do not account for the complex interaction with the adjacent open ocean. In this study, a global ocean general circulation model and biogeochemistry model were set up with a distorted grid providing a maximal resolution for the NW European shelf and the adjacent northeast Atlantic.

Using model climate projections we found that already a moderate warming of about $2.0 \mathrm{~K}$ of the sea surface is linked with a reduction by $\sim 30 \%$ of the biological production on the NW European shelf. If we consider the decline of anthropogenic riverine eutrophication since the 1990s, the reduction of biological production amounts is even larger. The relative decline of NW European shelf productivity is twice as strong as the decline in the open ocean $(\sim 15 \%)$. The underlying mechanism is a spatially well confined stratification feedback along the continental shelf break. This feedback reduces the nutrient supply from the deep Atlantic to about $50 \%$. In turn, the reduced productivity draws down $\mathrm{CO}_{2} \mathrm{ab}-$ sorption in the North Sea by $\sim 34 \%$ at the end of the 21 st century compared to the end of the 20th century implying a strong weakening of shelf carbon pumping. Sensitivity experiments with diagnostic tracers indicate that not more than $20 \%$ of the carbon absorbed in the North Sea contributes to the long-term carbon uptake of the world ocean. The rest remains within the ocean's mixed layer where it is exposed to the atmosphere.
\end{abstract}

The predicted decline in biological productivity, and decrease of phytoplankton concentration (in the North Sea by averaged $25 \%$ ) due to reduced nutrient imports from the deeper Atlantic will probably affect the local fish stock negatively and therefore fisheries in the North Sea.

\section{Introduction}

Because of their high biological productivity shelves have been proposed to play a major role in the absorption of atmospheric $\mathrm{CO}_{2}$ by fixing dissolved inorganic carbon (DIC) into organic soft tissue which lowers sea water $p \mathrm{CO}_{2}$ and draws $\mathrm{CO}_{2}$ from the atmosphere into the water. Therefore, most mid- and high-latitude shelves have been recognized to be significant sinks for atmospheric $\mathrm{CO}_{2}$ (e.g. Chen and Borges, 2009). Part of the carbon is exported to the open ocean. Therefore, Tsunogai et al. (1999) proposed the term "continental shelf pump" to describe an additional carbon pump mechanism besides the carbonate and the soft tissue pumps (Raven and Falkowski, 1999). From local case studies in the East China Sea and the North Sea it has been estimated that the shelf pump may account for 30 to $50 \%$ of the global ocean's net annual carbon uptake (Tsunogai et al., 1999; Thomas et al., 2004). The North Sea, which constitutes a significant area within the NW European shelf, has likewise been intensely monitored during the last decades and was found to be a significant sink for atmospheric carbon (e.g. Thomas et al., 2004).

Besides its role in the carbon cycle, continental shelves are also important for economic fisheries as they support over $90 \%$ of global fish catches (Pauly et al., 2002). There is much 
evidence that some fish populations and fish recruitment are highly vulnerable to climate due to changing water temperature and planktonic ecosystems (Beaugrand, 2004). In recent years additional evidence was provided that changes in primary production and phytoplankton abundance can influence fish stocks (Chassot et al., 2010; Friedland et al. 2012).

Biological production depends on the availability of nutrients, which are supplied to the shelf by upwelling and lateral advection from the deep ocean, and by continental runoff (Moll and Radach, 2003). The nutrient supply from the deep ocean depends strongly on the wind driven vertical mixing on the adjacent continental slope (Huthnance et al., 2009) and on the slope-current driven downward Ekman transport (Holt et al., 2009).

In most regional modelling studies the important processes on the adjacent open ocean are not sufficiently accounted for as the respective model domains do not include the continental slope (e.g. Paetsch and Kühn, 2008; Adlandsvik, B., 2008; Kühn et al., 2010; Skogen et al., 2011; Lorkowski et al., 2012). Global models on the other hand do not resolve the shelf seas sufficiently.

In this paper we address the future evolution of nutrient transport from the Atlantic into the North Sea and subsequent changes in biological productivity in response to the anthropogenic climate change as predicted for the 21 st century. To overcome the aforementioned specific problems associated with both regional and global models, in this study a global ocean general circulation model (OGCM) with gradually increased resolution on the NW European shelf coupled to a marine biogeochemistry and carbon cycle model is established and applied for future climate projections.

\subsection{Modelling approach}

A principal problem in regional modelling is associated with the choice of appropriate domain borders and lateral boundary climatologies.

To account for variabilities at the domain margins, either data from ocean reanalysis or from ocean models driven by atmospheric reanalysis data have been used widely (e.g. Winter and Johanessen, 2009; Prowe et al., 2009; Kühn et al., 2010; Wakelin et al., 2012; Holt et al., 2009; Lorkowski et al., 2012, Artioli et al., 2012). These data are often bias corrected and they are not available for future scenarios.

For studies focusing on climate change usually the output of climate models is used (e.g. Holt et al., 2010; Olbert et al., 2011; Holt et al., 2012; Wakelin et al., 2012). However, regional models have to resolve much more small-scale dynamics compared to global models and, with particular regard to biogeochemistry models, they also include more processes which makes these models computationally more expensive. Therefore, most studies investigating climate impact on the NW European shelf had to concentrate on specific time slices of only a few years (e.g. Holt et al., 2010, 2012; Wakelin et al., 2012). Given the fast adaption time of shal- low shelves compared to the open ocean this is appropriate but makes it difficult to analyse the full transient behaviour of dynamical processes at the shelf-open ocean boundary. So far, only few studies have carried out transient simulations for the full historical period and future scenarios for the 21st century. For the Baltic Sea, an enclosed sea with limited exchange with the rest of the ocean, transient simulations from 1961 to 2099 have been conducted (Meier et al., 2012)

Here we apply a global ocean and marine biogeochemistry general circulation model (OGCM) for a simulation of the full historical period and the SRES (Special Report on Emissions Scenarios) A1B scenario from 1860 to 2100. The advantage of this approach is that it resolves the full transient behaviour of dynamic processes at the shelf edge without applying any static boundary conditions for temperature, salinity, and nutrients.

Our approach is not the first attempt to apply a global model on shelves. An early attempt to take shelves into the focus of a global model was undertaken by Yool and Fasham (2001). The authors implemented into a physical OGCM a simple parameterization for carbon uptake on shelves based on observations in the East China Sea (Tsunogai et al., 1999) and investigated the carbon export to the open ocean in order to test the carbon shelf pumping hypothesis.

There are of course some structural limitations associated with our approach. Due to the long internal timescale of the global carbon cycle the model has to be spun up for several thousand years. Thus, this approach is computationally very expensive. As applying the forcing from any different global atmospheric model would require a new spin up, applying this downscaling technique to multiple global atmospheric models is hardly feasible. Our approach has the advantage of a proper treatment of the exchange between the shelves and the rest of the ocean and thus reduces this uncertainty. However, the disadvantage is that it becomes rather difficult to deal with the uncertainties arising from the choice of only one specific global climate model. The present model study is a first attempt to apply such a set-up to downscaling of anthropogenic climate change including a biogeochemical model. The focus of this paper lies more on the principal mechanisms involved rather than on an exact prediction of the effects of anthropogenic climate change for the ecosystem of the North Sea.

Furthermore, there are some small-scale processes controlled by the topography along the shelf break, which is marked by abrupt depth changes, steep ridges and deep channels, that are not sufficiently resolved by our model. Here, tidally induced internal waves and turbulent eddies stimulate intense upward mixing of dissolved nutrients (New and Pingree, 1990). Such processes are characteristic for the NW European shelf (e.g. Pingree and Mardell, 1981; Joint et al., 2001; Green et. al., 2008; Bergeron and Koueta, 2011) and thus, may influence nutrient supply to the shelf.

Likewise, our model does not include the process of sediment laden dense water cascading flows (DSWC), which 
have the potential to efficiently transport organic matter from the upper continental shelf to deeper layers. Thus, they may be important for the efficiency of the shelf carbon pump. Such processes have been shown to be locally important in the Gulf of Lion (Canals et al., 2006). However, we assume that in the North Sea DSWCs will play only a minor role, since the North Sea is a relatively vast and flat shelf compared to the narrow and small shelf in the Gulf of Lion. Eventually such processes might play a role along the Norwegian trench.

\section{Model description}

\subsection{The physical global ocean circulation model}

The physical model is the Max Planck Institute for Meteorology global primitive equation OGCM (MPIOM). It is a $z$-level model with a free surface. The model assumes the hydrostatic and Boussinesq approximations. It includes a dynamic thermodynamic sea ice model following Hibler (1979). Tracer and momentum advection follows a secondorder total variation diminishing scheme after Sweby (1984). The model's equations are discretized on a bipolar orthogonal curvilinear $\mathrm{C}$ grid. The water column is subdivided by 30 levels, eight of which lie within the uppermost $100 \mathrm{~m}$. MPIOM includes no explicit turbulence closure. The vertical eddy viscosity and tracer diffusion follows the parameterization of Pacanowski and Philander (1981, PP hereafter). Since this scheme underestimates mixing close to the surface an additional parameterization for wind stirring is included (Jungclaus et al., 2006). A detailed model description and validation of physical properties is given in Marsland et al. (2003).

For the specific application on the NW European shelf the model's grid has been set up with a resolution of nominal $1.5^{\circ}$ and the grid poles are placed over central Europe $\left(49^{\circ} \mathrm{N}\right.$, $\left.8^{\circ} \mathrm{E}\right)$ and North America $\left(44^{\circ} \mathrm{N}, 89^{\circ} \mathrm{W}\right)$ in order to maximize the resolution for the NW European shelf $(10 \mathrm{~km}$ in the German Bight) and for the adjacent North Atlantic. Figure 1 shows the model domain of the applied grid set-up focusing on the NW European shelf/North Atlantic. As the tidal movement is important both, for vertical mixing, and for the transport by the residual currents on continental shelves, the full potential of lunisolar tidal forces is prescribed according to Thomas et al. (2001). The appropriate simulation of tidal effects requires a relatively short time step of $45 \mathrm{~min}$. A detailed and comprehensive description of the physical set-up will be given in Sein et al. (2013).

\subsection{The carbon cycle and biogeochemistry model}

Embedded in the physical model is the biogeochemical module HAMOCC (HAMburg Ocean Carbon Cycle model, Wetzel et al., 2005), i.e. it uses the same grid configuration as MPIOM and the advection and diffusion of biogeochemical tracers are identical to temperature and salinity.

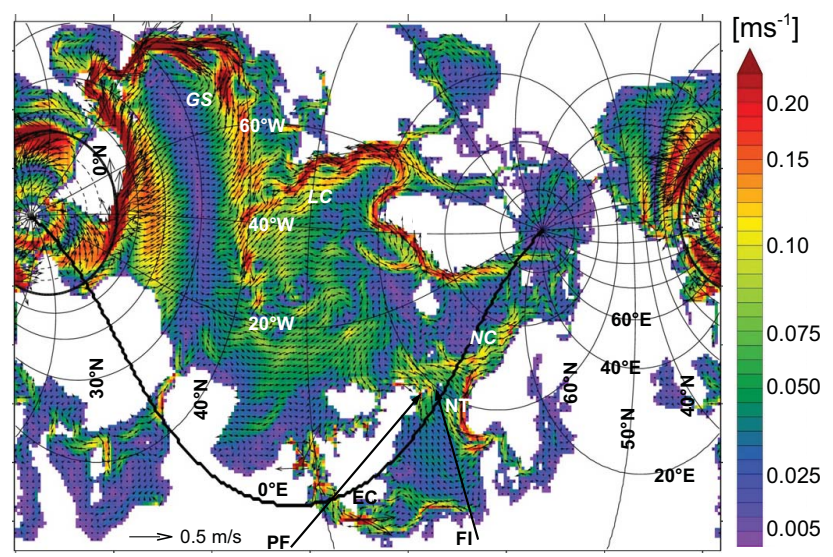

Fig. 1. Model domain. The zero meridian is indicated by the thick line. Also shown: surface circulation averaged over 1990-1999. Only every fourth vector is shown. EC is English Channel, NT is Norwegian Trench, PF is Pentland Firth, FI is Faire Island, NC is Norwegian Current, LC is Labrador Current, GS is Gulf Stream.

HAMOCC is a modified nutrient, phytoplankton, zooplankton, detritus (NPZD-type) biogeochemistry model. In case of sufficient light, phytoplankton growth is limited by dissolved phosphate $\left(\mathrm{PO}_{4}\right)$, nitrate $\left(\mathrm{NO}_{3}\right)$, or iron, which are fixed into organic soft tissue together with DIC following Redfield stoichiometry during photosynthesis. The growth rate is further dependent on water temperature (Eppley, 1972). The detritus pool is formed by dead phyto- and zooplankton and fecal pellets. Besides these biomass groups, dissolved organic matter is formed from excretion of living biomass. All organic matter is remineralized to inorganic constituents by consumption of oxygen or alternatively, by reduction of nitrate (denitrification) or eventually sulphate when not enough oxygen is available. At the sea floor the model is closed by a 12 layer sediment model following Heinze et al. (1999). Within the sediment, organic matter is further decomposed by consuming either oxygen or nitrate. Porewater phosphate, nitrate, and DIC is exchanged with the bottom layer using constant diffusion coefficients. Air-sea gas exchange for oxygen, nitrogen, and carbon dioxide is calculated from the local air-sea difference of respective partial pressures according to Wanninkhof (1992) with an improved temperature dependency (Gröger and Mikolajewicz, 2011). A technical model description is provided by Maier-Reimer et al. (2005). A comprehensive and detailed description of the model's organic and inorganic carbon cycle as well as the included nitrogen and sulphur cycle along with a profound validation of global climatologies is given in Ilyina et al. (2013).

We also implemented global riverine inputs of $\mathrm{PO}_{4}, \mathrm{NO}_{3}$, $\mathrm{DIC}, \mathrm{Fe}$, and $\mathrm{Si}$ in the model. Mean values for riverine inputs were prescribed based on the estimates from a global data set (Meybeck and Ragu, 1995). With this configuration the coupled ocean-biogeochemistry model provides a resolution in 


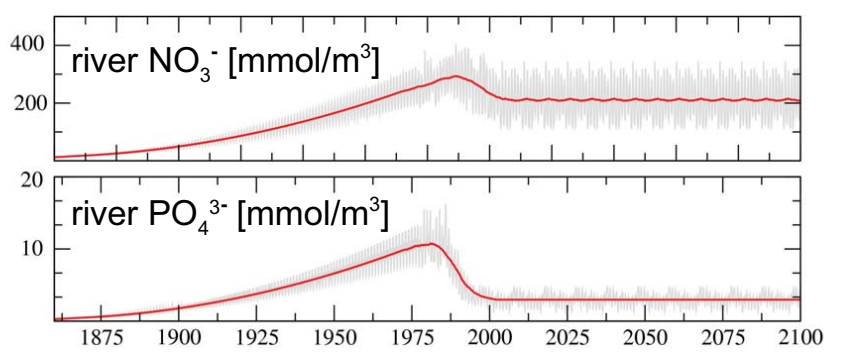

Fig. 2. Prescribed average concentration of riverine nutrient supply to the North Sea. Grey lines indicate monthly mean values. Red line indicates yearly mean values.

the area of interest which is comparable with many regional models (e.g. Moll and Radach, 2003).

In order to improve the model's performance in simulating the seasonal cycle of nutrients and phytoplankton we had to modify the light penetration scheme of the biogeochemistry model HAMOCC. Details of this light penetration scheme are given in the appendix.

\section{Experiments}

The model was spun up for several thousand years by forcing the model repeatedly with 6-hourly atmospheric fields taken from the ECHAM5/MPIOM IPCC AR 4 preindustrial control run (Roeckner et al., 2006). For the atmospheric forcing data no bias correction has been applied.

The experiments listed in Table 1 are designed to investigate the effects of climate warming, rising atmospheric $p \mathrm{CO}_{2}$, and anthropogenic eutrophication separately. For this, experiments CWE (climate warming effect), CWECEE (CWE-carbon emission effect), and CWE-CEE-AES (CWE-CEE-anthropogenic eutrophication scenario) were started and forced by the atmospheric output from the MPIECHAM5 IPCC AR 4 20th century and A1B scenario simulations between 1860 and 2100. In experiment CWE the pure effect of climate warming was tested by keeping the atmospheric $p \mathrm{CO}_{2}$ fixed at $288 \mathrm{ppm}$ for the biogeochemistry model. Experiment CWE-CEE includes also the rise of atmospheric $p \mathrm{CO}_{2}$ for the biogeochemistry model and run CWECEE-AES includes both, rising atmospheric $p \mathrm{CO}_{2}$ and an anthropogenic eutrophication scenario for the NW European shelf which today receives riverine nutrients from industrial agriculture. Thus, river concentrations of dissolved phosphorous and nitrate were exponentially increased between 1860 and 1976 to match observations available between 1976 and 2006 (updated data from Paetsch and Lenhart, 2004, Fig. 2). After 2006, monthly mean values from the last 5 years were repeated until 2100 . Thus, there is no trend in riverine nutrient supply during the 21 st century. We further note that our assumption of riverine eutrophication does not consider the changes during the two world wars. Thus, the period before
1976 is not analysed here. Run CTRL (control integration) continues the spin-up simulation, which allows the separation between real signals and residual model drift.

In addition, two sensitivity experiments were conducted to investigate the efficiency of the carbon shelf pump exemplary for the North Sea and the adjacent Atlantic (Table 1). In run $\mathrm{CO}_{2}-\mathrm{NS}$ atmospheric $p \mathrm{CO}_{2}$ was locally set to only $1112 \mathrm{ppm}$ over the North Sea, in order to study the effect on the global carbon cycle. Experiment MARKER was carried out to study the fate of North Sea water after it leaves the North Sea, i.e. does it really reach the deep ocean or does it remain within the ocean's mixed layer, where it is exposed to the atmosphere and subject to air-sea gas exchange. In ensemble experiment MARKER, 10 model runs were restarted from experiment CWE at the first of July in subsequent years from 1975 to 1984. In these experiments the North Sea water was homogeneously initialized with a tracer concentration of 1, whereas outside the North Sea the tracer was initialized with a concentration of 0 . The tracer concentration in subsurface layers was subject to advection and diffusion only. In the model's surface layer the tracer concentration was additionally altered by a simple air-sea gas exchange using a fixed air tracer concentration of 0 and a characteristic piston velocity of $100 \mathrm{myr}^{-1}$. The tracer inventory found outside the North Sea is thus an approximate measure for the potential of the North Sea shelf to really enrich the ocean with the tracer. We chose the 1st of July for starting the ensemble members because at this time the water column in the North Sea is strongly stratified. Thus, tracer rich-bottom waters are sheltered from exposure to the atmosphere at this time and have the highest potential to reach the open ocean.

\section{Model performance and validation}

Before applying the model to the IPCC A1B climate projection, the model's performance must be tested for both the global climatology, and the regional climatology in the area of interest in order to determine the extent to which the control period reproduces recent climate/ecosystem conditions. In the following section we validate the results of experiment CWE-CEE-AES as it includes both, the effects of rising atmospheric $p \mathrm{CO}_{2}$ and the anthropogenic eutrophication in the North Sea. Thus, this set-up is closest to reality. We concentrate primarily on the modelled distributions of dissolved nutrients since these variables integrate the different processes related to advection, diffusion, biological consumption and production, decomposition, remineralization, and temperature.

In the first part of the following section we compare the modelled global distributions with observation-based estimates from the World Ocean Atlas (WOA, Garcia et al., 2010). In the second part we test the model's performance particularly in the North Sea by visual and quantitative comparison to observations (Radach and Moll, 2006). 

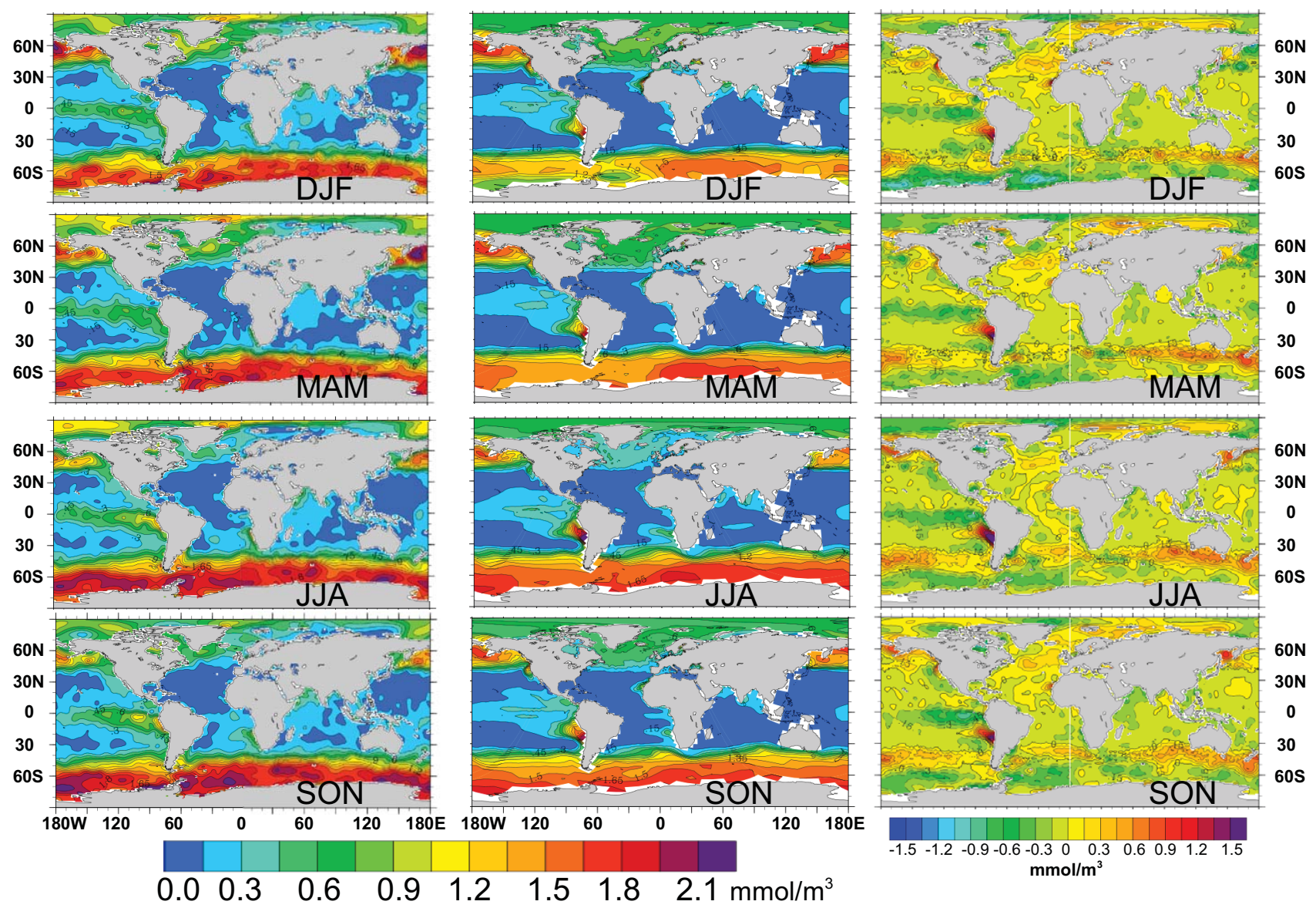

Fig. 3. Seasonal cycle of surface phosphate from observations from the World Ocean Atlas (left, Garcia et al., 2010), compared to model results (average for years 1993-2008, middle column), and modelled minus observed surface phosphate (right).

Table 1. Model experiments. CWE is climate warming effect, CEE is carbon emission effect, AES is anthropogenic eutrophication scenario.

\begin{tabular}{llll}
\hline Experiment & $p \mathrm{CO}_{2}$ & Eutroph. & Period \\
\hline CTRL & 288 & no & $\begin{array}{l}\text { without climate warming } \\
1860-2100\end{array}$ \\
& & & $1860-2100$ \\
$\mathrm{CWE}$ & 288 & no & $1860-2100$ \\
$\mathrm{CWE}-\mathrm{CEE}$ & $288-700 \mathrm{ppm}$ & no & $1860-2100$ \\
$\mathrm{CWE}-\mathrm{CEE}-\mathrm{AES}$ & $288-700 \mathrm{ppm}$ & yes & $1980-2000$ \\
$\mathrm{CO}_{2}$-NS & $288 \mathrm{ppm}$ but NS: $1112 \mathrm{ppm}$ & no & 10 runs of 5 yr integration \\
MARKER & $288 \mathrm{ppm}$ & no & \\
\hline
\end{tabular}

${ }^{1}$ Ensemble runs were started on 1 July 1975, 1 July 1976, ...1 July 1979.

\subsection{Global ocean}

The global patterns of dissolved nitrate and phosphate are very similar since HAMOCC models' biological nutrient uptake strictly according to the Redfield ratio and nitrogen specific processes such as $\mathrm{N}_{2}$ fixation and denitrification are tied to local environments. We here therefore concentrate primarily on the modelled distribution of dissolved phosphate. The global distribution of nutrients is similar to the one validated in Ilyina et al. (2013). Therefore, for nitrate the reader is referred to the paper mentioned above.

In general, the modelled surface phosphate concentration compares well with observed patterns (Fig. 3). Highest concentrations are located in the northernmost Pacific, where nutrient rich abyssal waters rise, and in the high latitude Southern Ocean where deep convection around Antarctica maintains nutrient supply from deeper layers (Maier-Reimer, 

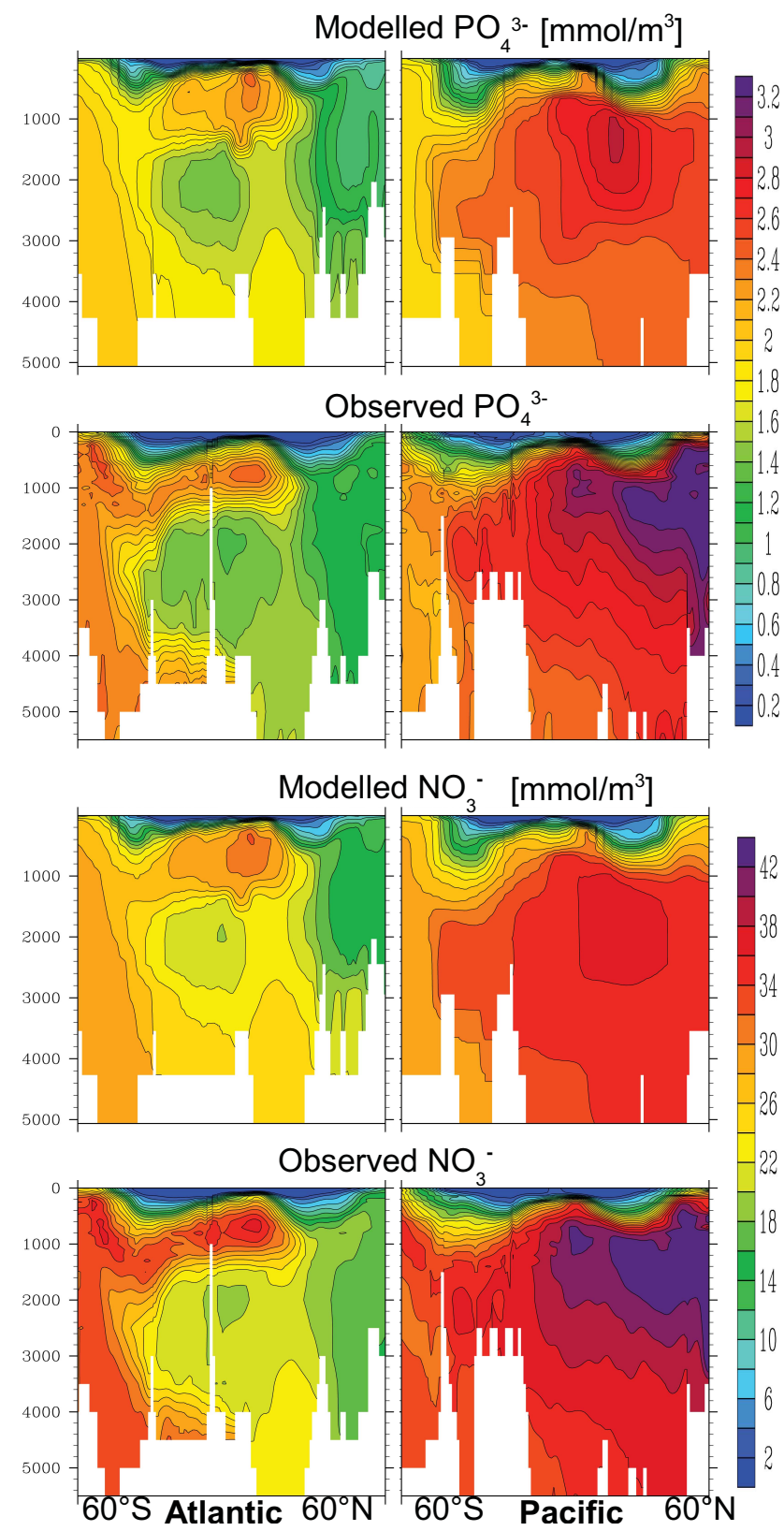

Fig. 4. Modelled annual mean distributions for phosphate (a) and nitrate (b) along $35^{\circ} \mathrm{W}$ (Atlantic, left) and $180^{\circ} \mathrm{E}$ (Pacific, right) compared to observations from the World Ocean Atlas (Garcia et al., 2010).

1993). In these two regions the model clearly underestimates phosphate concentrations, which results probably from an overestimation of biological consumption due to a tooweak iron limitation (Ilyina et al., 2013). Enhanced concentrations are also associated with the wind-driven eastern Pacific equatorial divergence, and the upwelling along the coasts of western Africa and western South America (MaierReimer, 1993). The northern North Atlantic is marked by a pronounced seasonal cycle, which is mainly caused by the nutrient-consuming biological production during spring and summer and nutrient accumulation during winter (Fig. 3). Lowest concentrations are seen in the subtropical gyres which are marked by downward Ekman pumping and a thin mixed layer (Maier-Reimer, 1993; Wetzel, 2004).

The vertical nutrient distributions are shown in Fig. 4. The main deep and intermediate waters can be well recognized by their nutrient content. Along the Atlantic section North Atlantic Deep Water (NADW) causes low nutrient concentrations between 1800 and $4000 \mathrm{~m}$ water depths. This water mass is formed with a large component of nutrientdepleted surface water originating from the subtropical Atlantic (Broecker and Peng,1982; Maier-Reimer, 1993). The meridional overturning circulation of the model $(14 \mathrm{~Sv}$ depicted at $26.5^{\circ} \mathrm{N}$ ) is in the lower range of published modelled values (10 to $20 \mathrm{~Sv}$, e.g. Persechino et al., 2012; Jungclaus et al., 2013) and from a 4-year observational campaign (18.7 Sv Kanzow et al., 2010). Below the NADW, Antarctic Bottom Water can be recognized by higher phosphate concentrations. This is an older, poorly ventilated water mass which has gained a lot of nutrients by remineralization of organic matter (Broecker and Peng, 1982; MaierReimer, 1993). In the Southern Ocean at deeper layers the nutrient content is slightly underestimated. Pronounced features of the Atlantic section are the nutrient rich Antarctic Intermediate Water which gains nutrients by remineralization of organic matter (Maier-Reimer, 1993), and the North Atlantic where nutrient-depleted surface waters are transferred to depth due to deep convection (Maier-Reimer, 1993) and spread southward as NADW. Due to the conveyor belt circulation the Pacific ocean is generally nutrient richer compared to the Atlantic (Broecker, 1991). This feature is is well reproduced by the model. The highest nutrient concentrations are reached in the North Pacific at intermediate depths between 1000 and $2000 \mathrm{~m}$. This is underestimated by the model. In both, the Atlantic and Pacific Ocean, Ekman pumping in the subtropical gyres transfers nutrient depleted surface waters to depths (Maier-Reimer, 1993). In the Pacific, the Southern Hemisphere's subtropical convergence cell extents deeper than the one in the Northern Hemisphere, which compares well with observations from the WOA. Globally integrated fluxes of $\mathrm{CO}_{2}$, primary production, and export production are well within the range of published values (Table 3 ).

\subsection{North Sea}

For a realistic simulation of biogeochemical cycles it is essential to model a realistic flow pattern not only for the North Sea but for the adjacent open Atlantic as well. Atlantic waters enter the North Sea mainly at its northern boundary through the straits of Fair Isle and Pentland Firth and through the English Channel in the southwest (Fig. 1). Waters leave the North Sea along the Norwegian trench and are further transported towards the Arctic via the Norwegian Current. The modelled water mass net exchange along the 

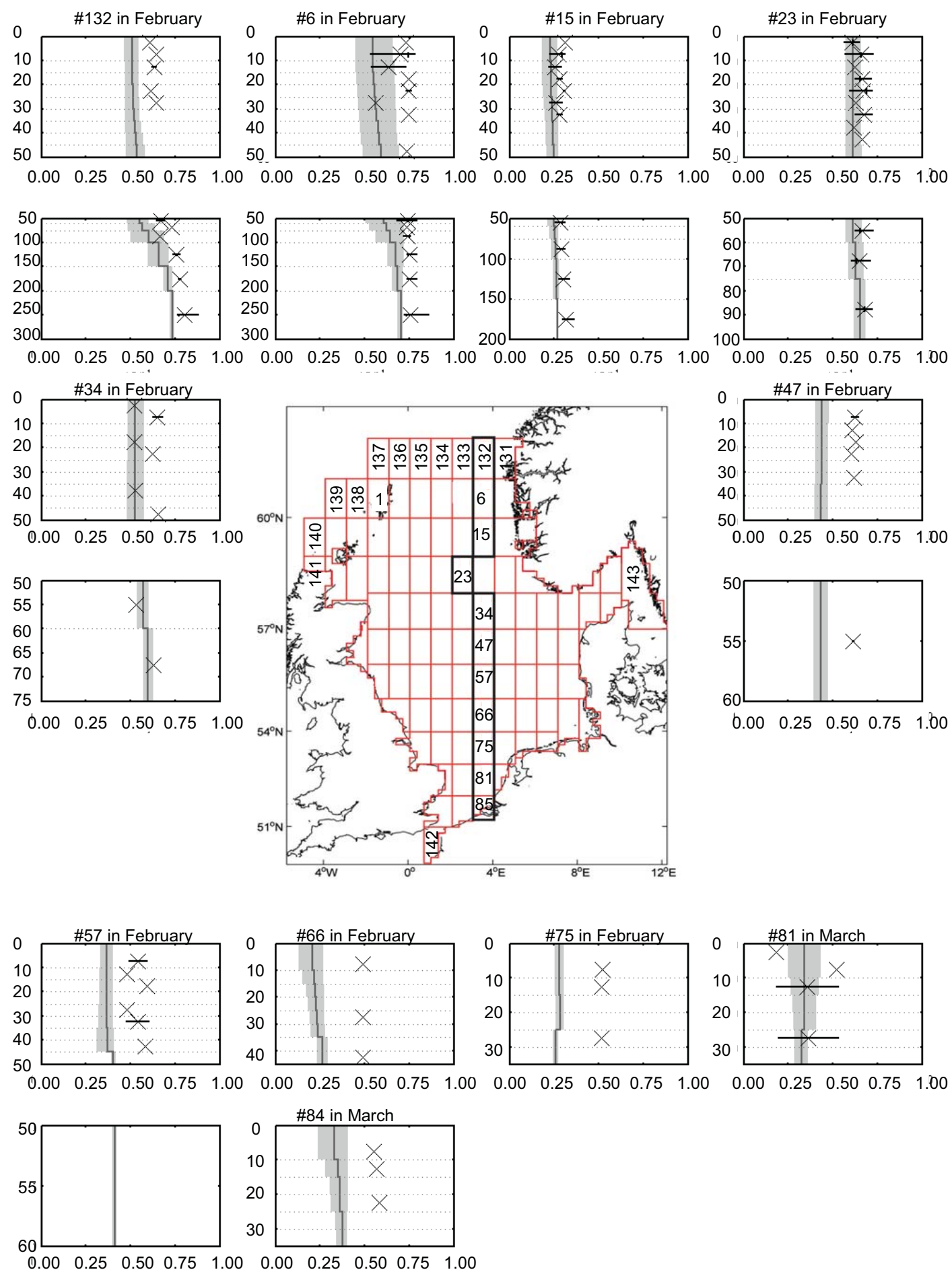

Fig. 5a. North-south transect of simulated and observed state variables as vertical profiles through the North Sea along the marked boxes. Climatological monthly means are shown for the period 1993-2008. Observations from MUDAB (Große and Moll, 2011) are indicated by crosses together with minimum and maximum bars. Simulations are indicated by the solid line. Variability is indicated by the 17 and $83 \%$ percentiles as shading around the solid line. The profiles begin with the most northern box in the top left corner and end in the most right subplot at the bottom. Vertical profiles with data observed deeper than $50 \mathrm{~m}$ are separated into two plots for a better resolution. The lower part of the profile is always positioned directly below the upper part. Concentration on the $\mathrm{x}$-axis is mmol $\mathrm{m}^{-3}$. (a) Dissolved phosphate in winter. 

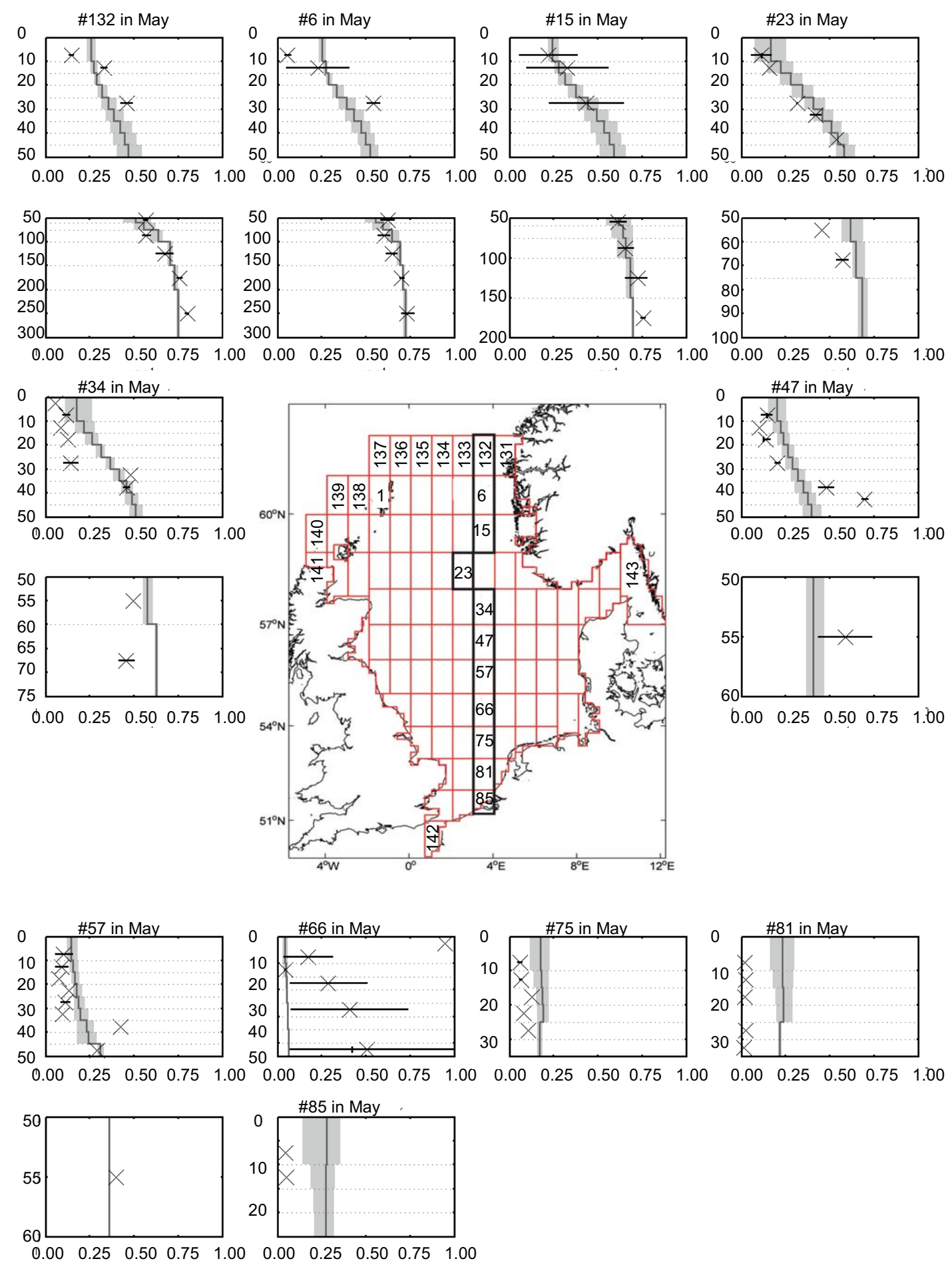

Fig. 5b. Continued. Same as (a) but for dissolved phosphate in spring. 

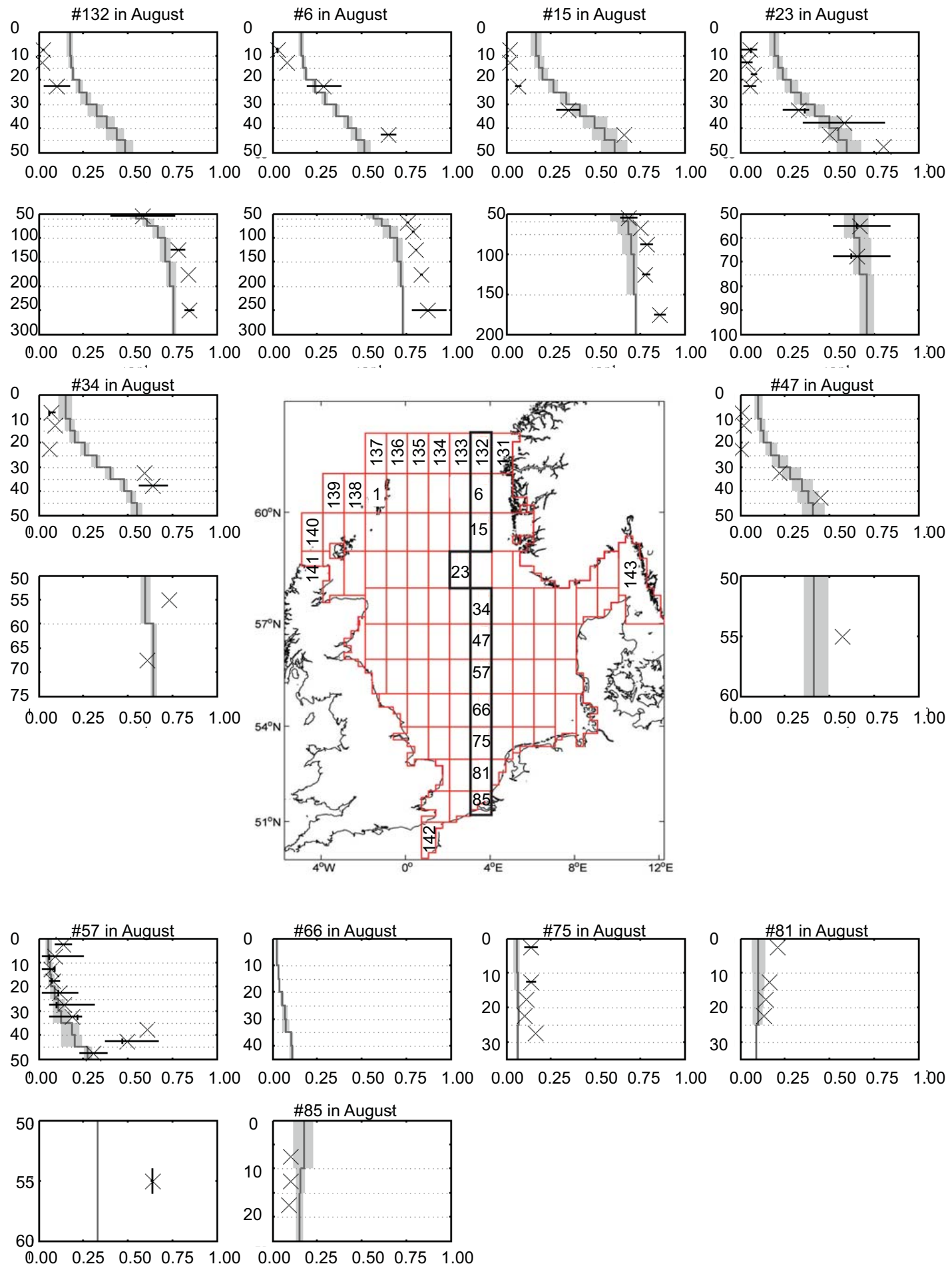

Fig. 5c. Continued. Same as (a) but for dissolved phosphate in summer. 

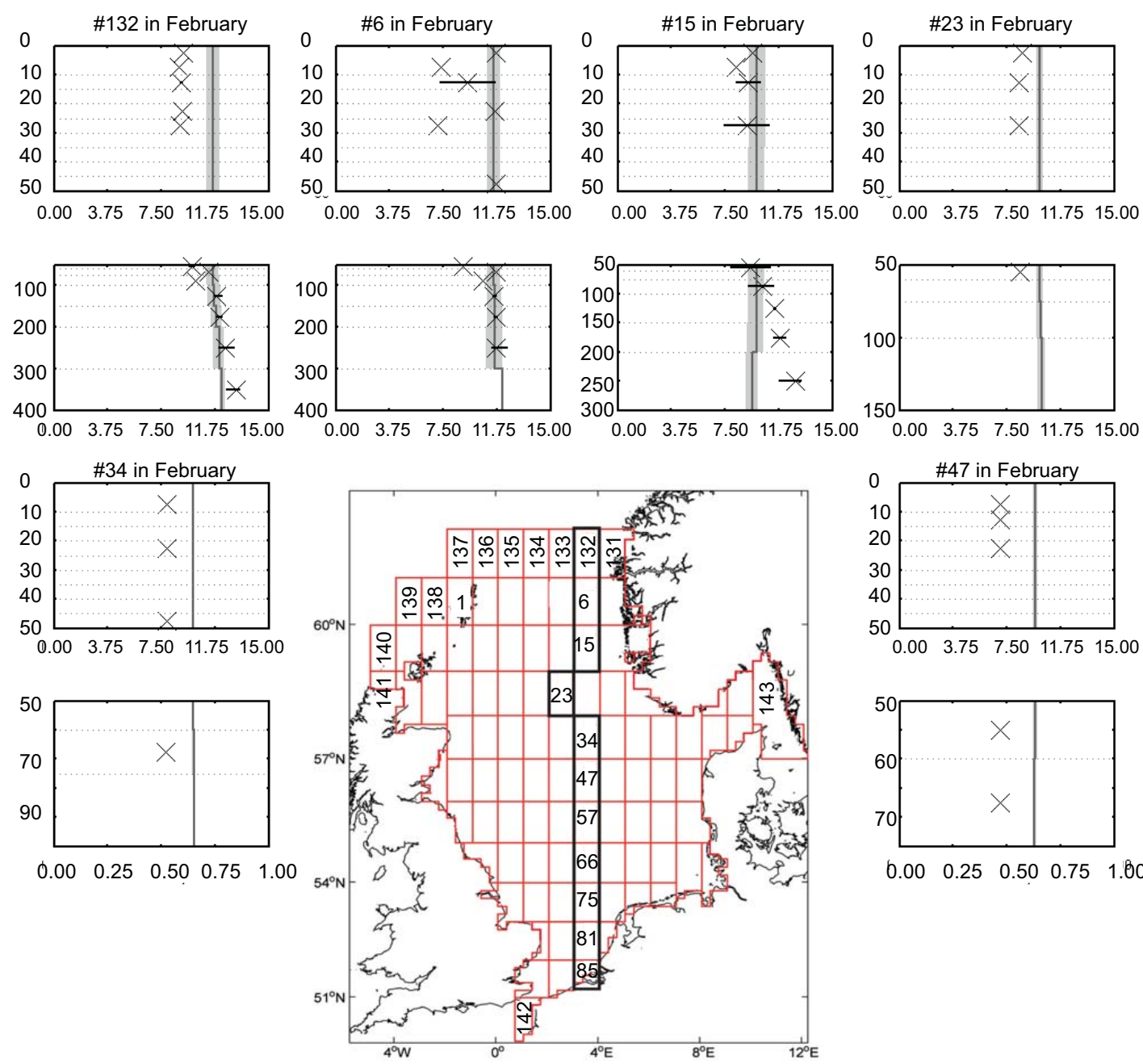

$\begin{array}{lllll}0.00 & 0.25 & 0.50 & 0.75 & 1.00\end{array}$
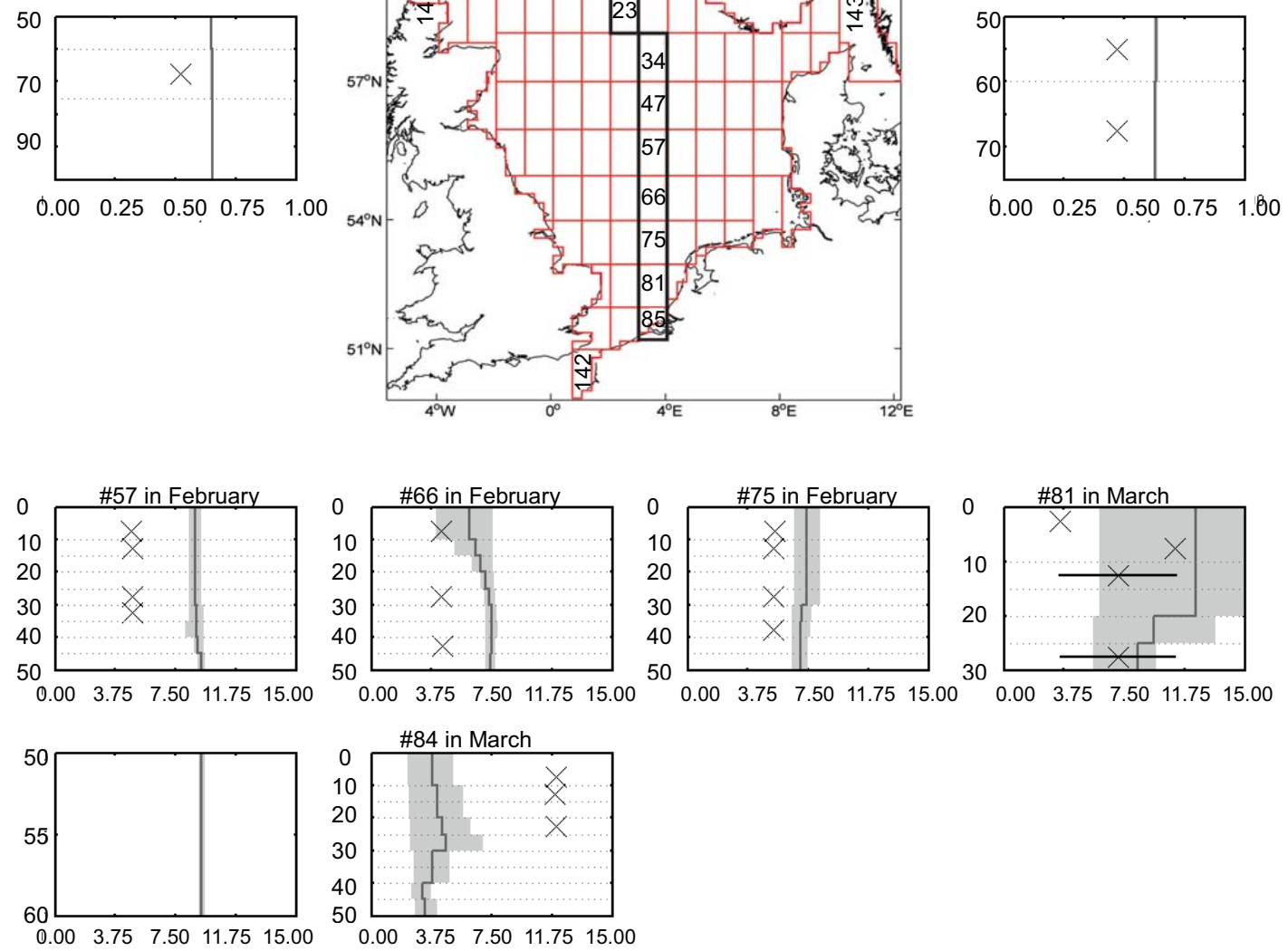

Fig. 5d. Continued. Same as (a) but for dissolved nitrate in winter. 

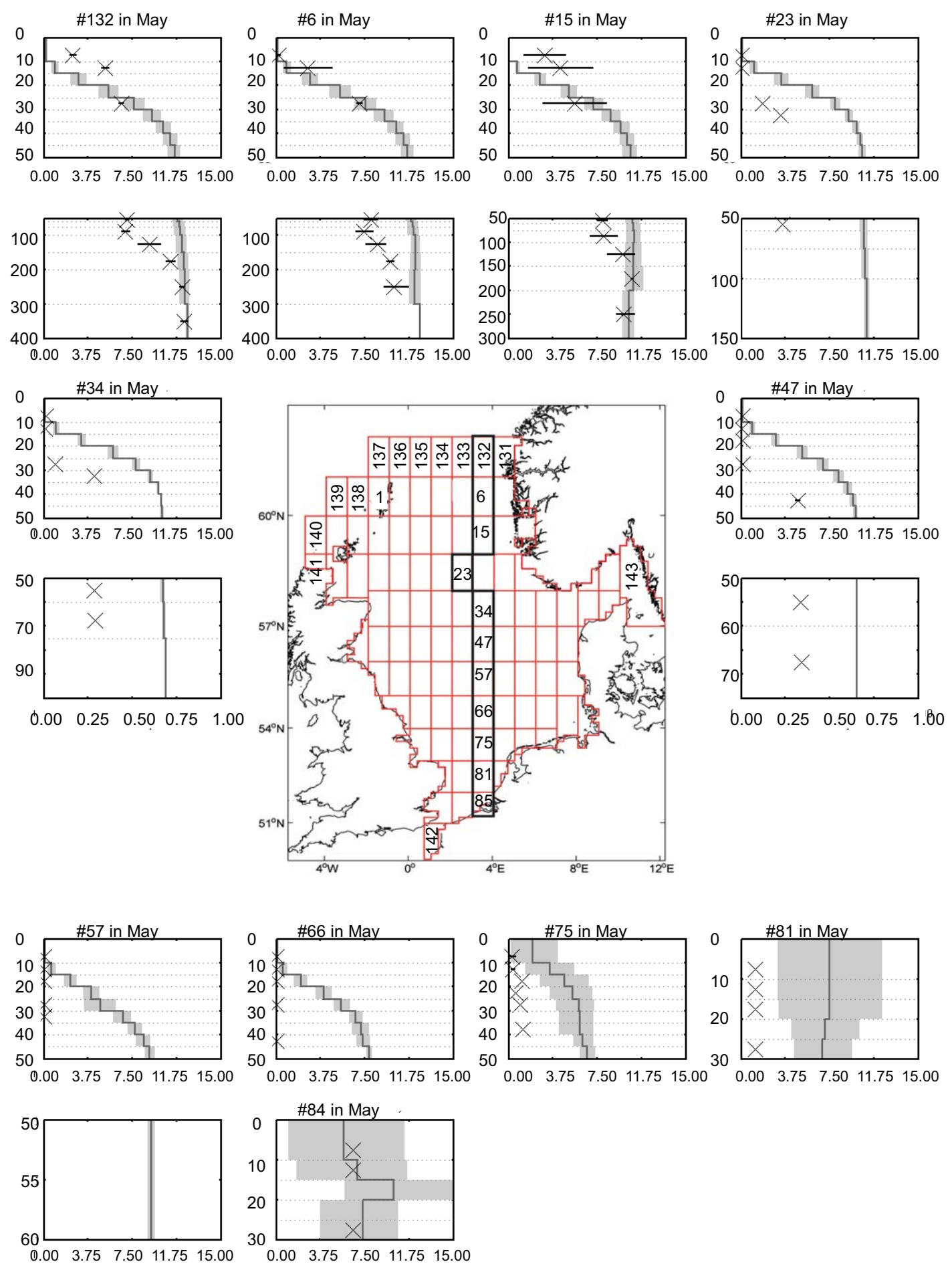

Fig. 5e. Continued. Same as (a) but for dissolved nitrate in spring. 

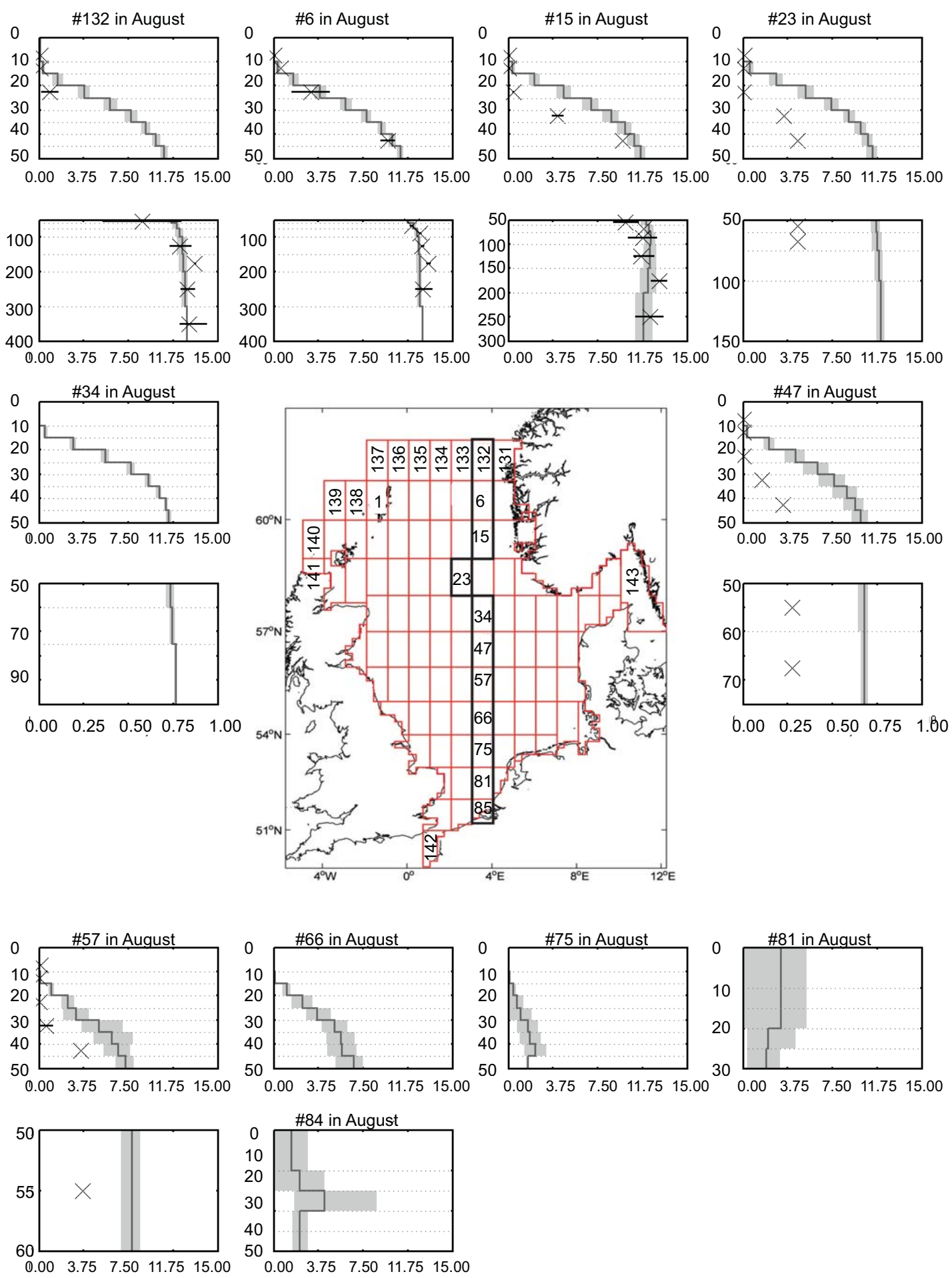

Fig. 5f. Continued. Same as (a) but for dissolved nitrate in summer. 

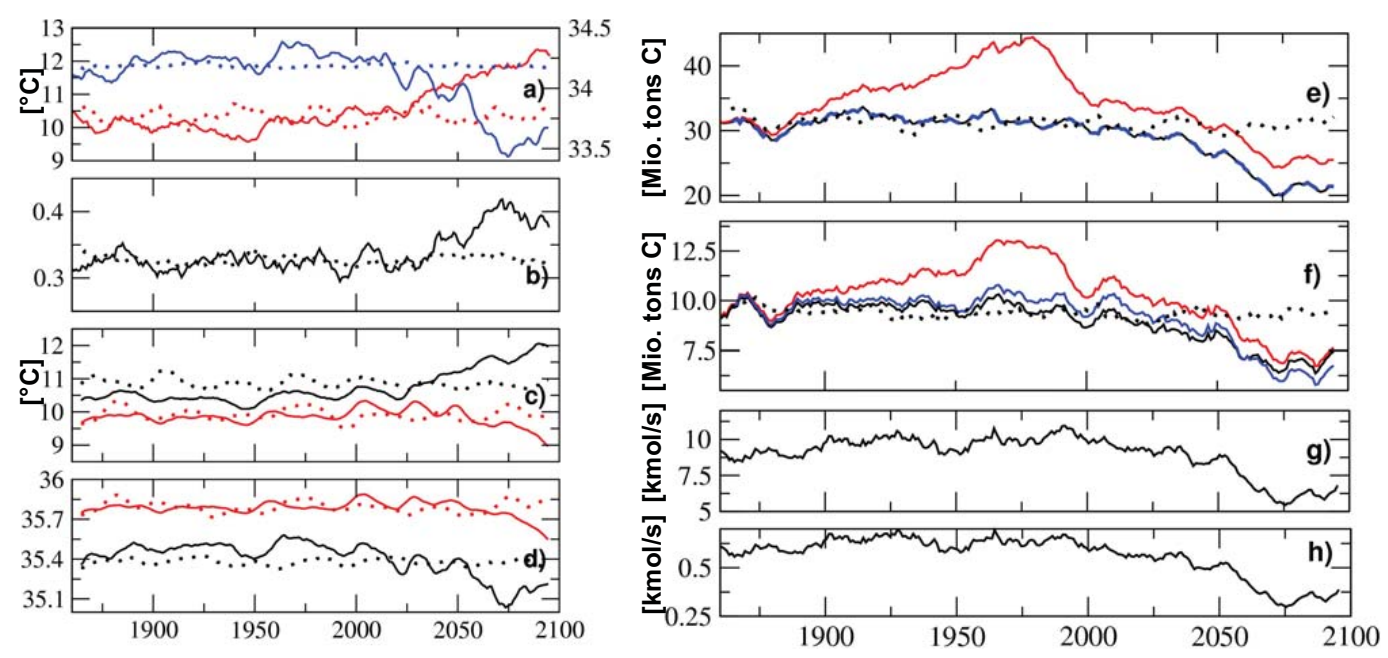

Fig. 6. (a) Annual mean of surface temperature (red) and salinity (blue) averaged over the North Sea. Dotted lines indicate the control integration CTRL, (b) annual mean bottom-surface salinity difference averaged over the North Sea, (c) 0-100 m (black) and 614-713 m (red) water temperature averaged over the continental slope northwest of the North Sea $\left(12^{\circ} \mathrm{W}-6^{\circ} \mathrm{W} ; 56^{\circ} \mathrm{N}-61^{\circ} \mathrm{N}\right.$, indicated by the red box in Fig. 7), (d) same as (c) but for salinity, (e) yearly primary production integrated over the North Sea. Dotted lines indicate the control integration CTRL, (f) carbon absorption of the North Sea (Mt C). Dotted lines indicate the control integration CTRL, (g) winter gross mass transports of nitrate into the North Sea calculated from experiment CWE, (h) same as (g) but for phosphate. Note: hydrographic properties in (a-d) are the same in all scenario experiments.

Table 2. Budgets of absorption (defined as net $\mathrm{C}$ flux into the water column in million tons of carbon) and biological production (million tons of carbon) for the North Sea calculated over the last two decades of the 20th and 21 st centuries. Numbers in brackets indicate budgets calculated for the entire NW European shelf (all areas between $37^{\circ} \mathrm{N}$ and $65^{\circ} \mathrm{N}$ adjacent to the North Atlantic and shallower than $200 \mathrm{~m}$ ). Last two columns indicate the relative change from 1980-1999 to 2080-2099. PP is primary productivity.

\begin{tabular}{lrrrrrr}
\hline \multirow{2}{*}{ Experiment } & \multicolumn{2}{c}{$1980-1999$} & \multicolumn{2}{c}{$2080-2099$} & \multicolumn{2}{c}{ Relative change (\%) } \\
& PP & Absorption & PP & Absorption & PP & Absorption \\
\hline CWE & 31.07 & 9.3 & 21.68 & 7.15 & -30.22 & -23.11 \\
& $(84.74)$ & $(18.29)$ & $(60.81)$ & $(16.05)$ & $(-28.24)$ & $(-12.25)$ \\
CWE-CEE & 31.66 & 9.89 & 21.66 & 6.53 & -31.58 & -33.97 \\
& $(85.76)$ & $(21.16)$ & $(60.02)$ & $(16.61)$ & $(-30.01)$ & $(-21.50)$ \\
CWE-CEE-AES & 40.04 & 11.80 & 25.82 & 7.43 & -35.51 & -37.03 \\
& $(130.29)$ & $(29.52)$ & $(79.04)$ & $(20.03)$ & $(-39.34)$ & $(-32.15)$ \\
\hline
\end{tabular}

northern boundary and through the English Channel compares well with the observation based estimate of Thomas et al. (2005, see Table 3). Likewise, the net mass transports of carbon across the boundaries are in good agreement with observations. With the exception of the net carbon export across the northern boundary, differences between the modelled transports and the observations are clearly smaller than the model's standard deviation. The modelled absorption of atmospheric carbon amounts to 0.9 Teramol per year $\left(\mathrm{Tmol} \mathrm{yr}^{-1}\right)$. This corresponds to a mean absorption of $1.5 \mathrm{molc} \mathrm{m}^{-2}$, which is close to the estimate of $1.3 \mathrm{~mol} \mathrm{c} \mathrm{m}^{-2}$ given by Lorkowski et al. (2012) and the observation based estimate of Thomas et al. (2005) $\left(1.4 \mathrm{molc} \mathrm{m}^{-2}\right)$.

The model's annually integrated primary production amounts to $6.5 \mathrm{molc} \mathrm{m}^{-2}$. This is clearly lower compared to estimates by the HAMSOM/ECOHAM model which range between 12 and $18 \mathrm{molm}^{-2}$ (Moll, 1998; Moll and Radach, 2003; Kühn et al., 2010; Lorkowski et al., 2012). The lower biological production results from low benthic remineralization rates in the sediment. The remineralization rates have been originally parameterized to fit the vertical nutrient distribution in the open ocean. Thus, in the shallow North Sea too much organic detritus is deposited in the sediment. Likewise we did not include the atmospheric nitrogen deposition in our simulations (Paetsch and Kühn, 2008). Including the atmospheric nitrogen input would have enhanced the productivity strongly on the outer shelf which in our model is limited by nitrate whereas near the coast it is limited by phosphorous. 
a)

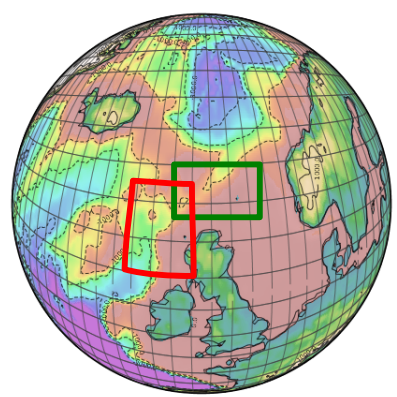

$[\mathrm{m}]$

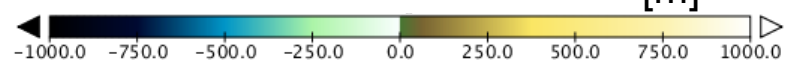

b)
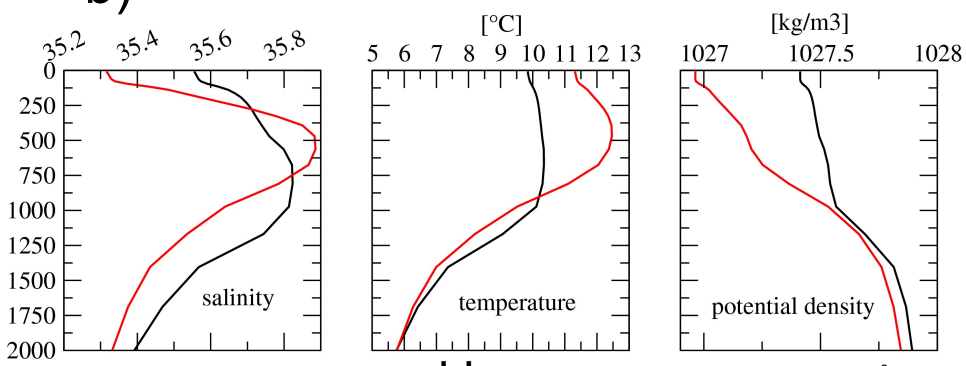

red box
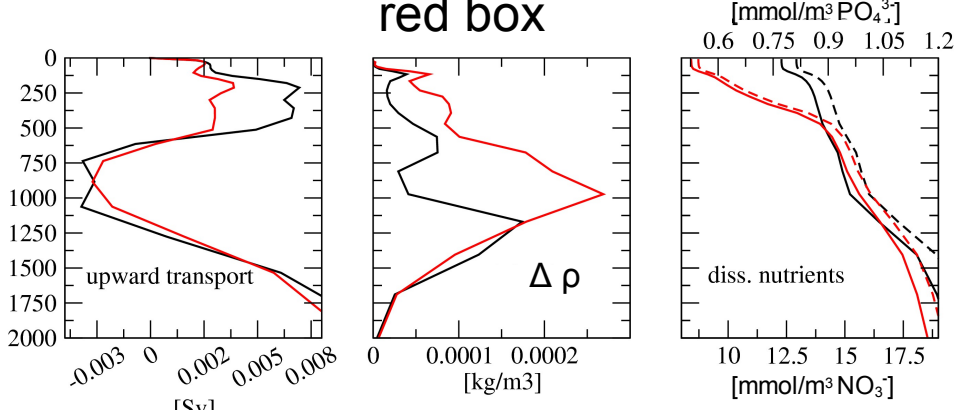

C)
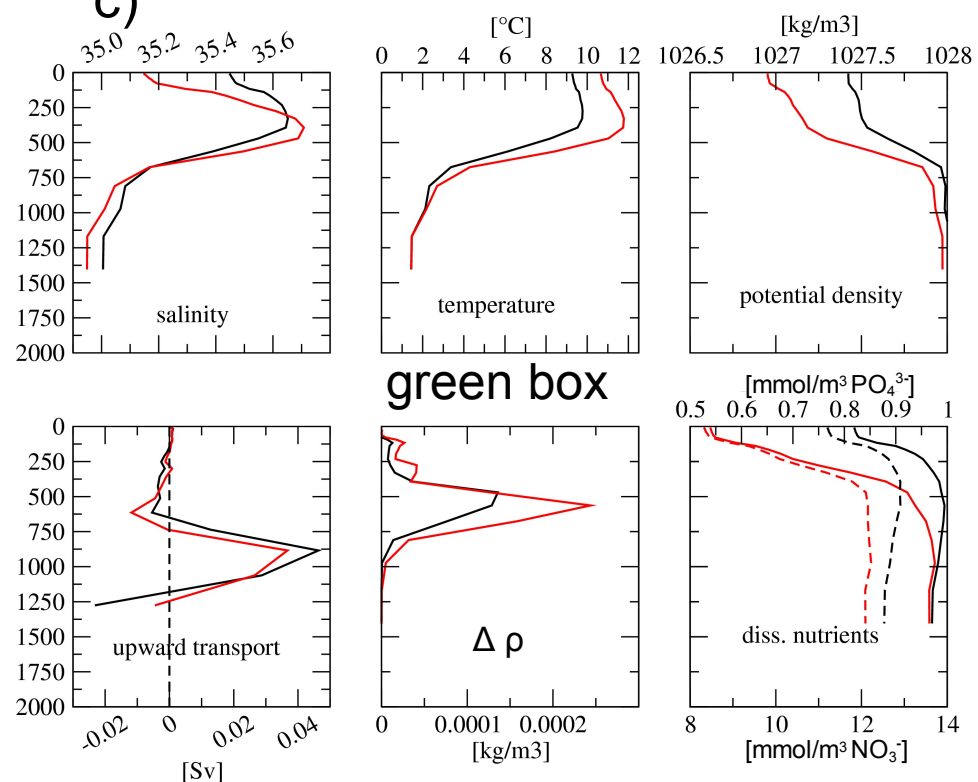

Fig. 7. (a) Position of red and green boxes used for averaging profiles in (b) and (c). (b) and (c) area-averaged vertical distribution of hydrographic parameters for the regions indicated by the red and green boxes in (a). Only those grid cells were considered where the water depth exceeds $500 \mathrm{~m}$. $\delta \rho$ denotes the difference in potential density between subsequent model levels. 
Table 3. Modelled global and regional mass fluxes averaged for the last decade of the 20th century. Mass fluxes for the North Sea refer to Thomas et al. (2005). NB is northern boundary, EC is English Channel, ATM is atmosphere, P-E is precipitation-evaporation.

\begin{tabular}{lll}
\hline Global & Other models & Model \\
\hline Primary production $\left(\mathrm{Pg} \mathrm{C} \mathrm{yr}^{-1}\right)$ & $24-49^{1}$ & 54 \\
Export production $\left(\mathrm{Pg} \mathrm{C} \mathrm{yr}^{-1}\right)$ & $5.0-9.9^{1}$ & 7.2 \\
Carbon uptake $1990-1999\left(\mathrm{Pg} \mathrm{C} \mathrm{yr}^{-1}\right)$ & $1.5-2.2^{2}$ & 1.55 \\
\hline North Sea & Observation & Model \\
& & \\
\hline Volume $_{\mathrm{NB}}(\mathrm{Sv})$ & -0.18 & $-0.19( \pm 0.05)$ \\
Volume $_{\mathrm{EC}}(\mathrm{Sv})$ & 0.15 & $0.17( \pm 0.04)$ \\
$\mathrm{P}-\mathrm{E}(\mathrm{Sv})$ & & $-0.02( \pm 0.004)$ \\
Carbon & & $-9.9( \pm 3.1)$ \\
Carbon $_{\mathrm{EC}}\left(\mathrm{Tmol} \mathrm{yr}^{-1}\right)$ & -13.3 & $9.0( \pm 3.9)$ \\
Carbon $_{\mathrm{ATM}}\left(\mathrm{Tmol} \mathrm{yr}^{-1}\right)$ & 10.7 & $0.9( \pm 0.008)$ \\
\hline
\end{tabular}

${ }^{1}$ Steinacher et al. (2010).

2 Orr et al. (2001).

Table 4. Statistics for a quantitative comparison of simulated and observed state variables derived from Taylor diagrams (Taylor, 2001). rms is root mean squared, corr is Pearson's correlation, stddev is standard deviation, $\mathrm{N}$ is number of observations. The statistics have been derived from all 155 boxes shown in Fig. 5. See text for details about data set and data handling.

\begin{tabular}{lccccc}
\hline State variable & rms & corr & stddev observation & stddev simulation & N \\
\hline Phosphate & 0.25 & 0.58 & 0.29 & 0.24 & 3529 \\
Nitrate & 6.10 & 0.43 & 6.00 & 5.50 & 2536 \\
Temperature & 1.20 & 0.94 & 3.40 & 2.90 & 5537 \\
Salinity & 0.75 & 0.76 & 1.10 & 1.10 & 5740 \\
\hline
\end{tabular}

\subsubsection{Quantitative results}

In the following we validate the model's spatial and temporal variability of temperature, salinity and dissolved nitrate and phosphate. For this we use observational data derived from the Marine Environmental Data Base (MUDAB) and the CANOBA (carbon and nutrient cycling in the North Sea and the Baltic Sea) data set.

MUDAB is a joint project of the Federal Maritime and Hydrographic Agency (BSH) in Hamburg and of the Federal Environmental Agency (UBA) in Berlin. It is managed by the German Oceanographic Data Center (www.bsh.de/en/marine_data/environmental_protection/ mudab_database/). CANOBA is a data set of carbon and nutrient measurements on a regular $1^{\circ} \times 1^{\circ}$ station grid for all four seasons between 2001-2002 (Thomas, 2002; Thomas et al., 2004) and additional data from other years.

We here validate a historical experiment. Therefore, in contrast to hindcast simulations forced by reanalysis data, we cannot compare individual years between observed and simulated quantities. The ECHAM atmosphere model used for forcing has its own short-term oscillations (such as the North Atlantic Oscillation) which are realistic by means of amplitudes and frequencies. However, they cannot be ex- pected to be in phase with reanalysis data that assimilated observations. Therefore, for the following quantitative validation we consider here salinity, temperature, and nutrient data for the period 1993-2008. For this period all available measurements for temperature $(n=5537)$, salinity $(n=5740)$, phosphate $(n=3529)$, and nitrate $(n=2536)$ were used. For the analysis, the North Sea was subdivided into single boxes of $1^{\circ} \times 1^{\circ}$ extension. Where appropriate, boxes were further subdivided for depths deeper and shallower than $30 \mathrm{~m}$ resulting in a total number of 155 boxes.

The distribution of available observations throughout the year, the boxes, and depth levels are given in the Supplement $\mathrm{S} 1$. The majority of observations originate from the upper $50 \mathrm{~m}$ and over $20 \%$ are sampled from the surface. The samples are nearly uniformly distributed over the 155 boxes. Nutrient data was built-up in temporal clusters in February, May, and August. Physical data are concentrated mainly in January, February, July, and August. The fewest data are available for autumn and from depths greater than $100 \mathrm{~m}$. For each month, box and depth level the following statistical parameters have been calculated from observational and modelled data: mean value, standard deviation, the 17 and $83 \%$ percentiles. In a first step we compare the statistical results along a south-north transect with the best data coverage 

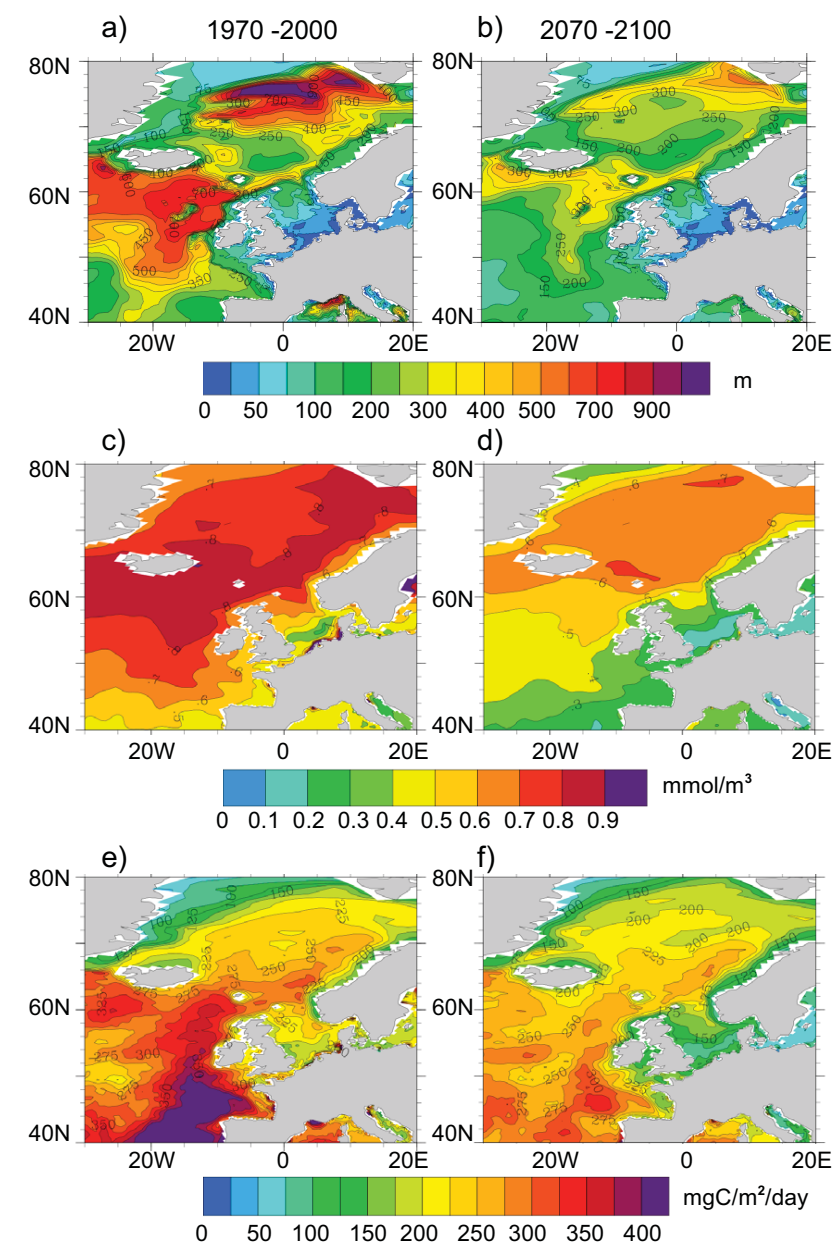

Fig. 8. (a) and (b) average winter (DJF) mixed layer depth at the end of the 20th and 21st centuries. (c) and (d) same as (a) and (b) but for average dissolved surface phosphate concentration. (e) and (f) same as (a) and (b) but for vertically integrated yearly mean primary production.

from shallow waters off the Rhine river to the boundary with the North Atlantic near the Norwegian trench. For this, we restricted the comparison to available data for winter-, spring-, and summer-representing conditions before, during, and after the spring bloom. Depending on the availability of observations we use either February or March data (winter), or July or August data (summer) for comparison of observations and modelled data in the respective boxes. The results are presented as mean profiles for the respective months in Fig. 5fa-f for phosphate and nitrate. In addition, winter and summer mean profiles for temperature and salinity are provided in the Supplement S2. Further details on the observational data sets and quantitative methods are given in Große and Moll (2011).

\subsubsection{February}

The winter situation is characterized by well-mixed conditions along the entire transect resulting in overall low vertical gradients seen in temperature, salinity, and nutrient concentrations (Supplement S2, Fig. 5fa, d). The model tends to slightly underestimate phosphate concentrations in the northern boxes $(132,6,15,23,34)$. Further south, the deviation from observations is more pronounced, which is probably linked to the uncertainty in applied river runoff that was calculated from the atmospheric forcing fields which cannot be expected to be in phase with observed data.

Nitrate concentrations are generally too high except for the deeper boxes (Fig. $5 \mathrm{fd}$ ) below $50 \mathrm{~m}$ where they fit well with or even slightly exceed observations. Observed and modelled data are most congruent for salinity and temperature where the modelled values are mostly within the range of observations (indicated by the 17 and $83 \%$ percentiles). In most boxes the temperature is slightly too low (Supplement).

\subsubsection{May}

In the northern North Sea both phosphate, and nitrate concentrations are substantially diminished in the upper $50 \mathrm{~m} \mathrm{com-}$ pared to the winter situation (Fig. $5 \mathrm{fb}$, e). Below the euphotic zone the changes are less pronounced and nitrate concentrations are even substantially higher than in winter. This pattern clearly reflects the spring bloom in the euphotic zone and the onset of stratified conditions in the northern North Sea and is well reproduced in the simulation. In the central North Sea (boxes 57, 66, and 75) the modelled phosphate and nitrate concentrations are different. While simulated phosphate shows in agreement with observations, very-low to zero gradients (except box 66 which has a very large range), simulated nitrate is nearly depleted near the surface but exhibits (contrary to observations), still, winter concentrations at 40 to $50 \mathrm{~m}$ depth (Fig. $5 \mathrm{fe}$ ). This may reflect the fact that nitrate is already limiting production at the surface in the simulation and the model's subsurface production is too weak. Observed nitrate concentrations are close to zero (while phosphate is concentrations are relatively high), which indicates that nitrate is a nutrient limiting factor. In the southernmost boxes 81 and 85 the water column is well mixed in agreement with observations (Fig. 5fe). Modelled concentrations are clearly too high in box 81 but match well in box 85 .

\subsubsection{August}

Both observations and model data indicate thermal stratification with a pronounced thermocline between 20 and $40 \mathrm{~m}$ (Supplement S2). Absolute temperatures and positition of the thermocline match very well with observations. Thermocline intensity and the depth of the thermocline increase towards the shallower southern region. Stratified conditions extend to approximately $54^{\circ} \mathrm{N}$ (box 66). With regard to salinity the 

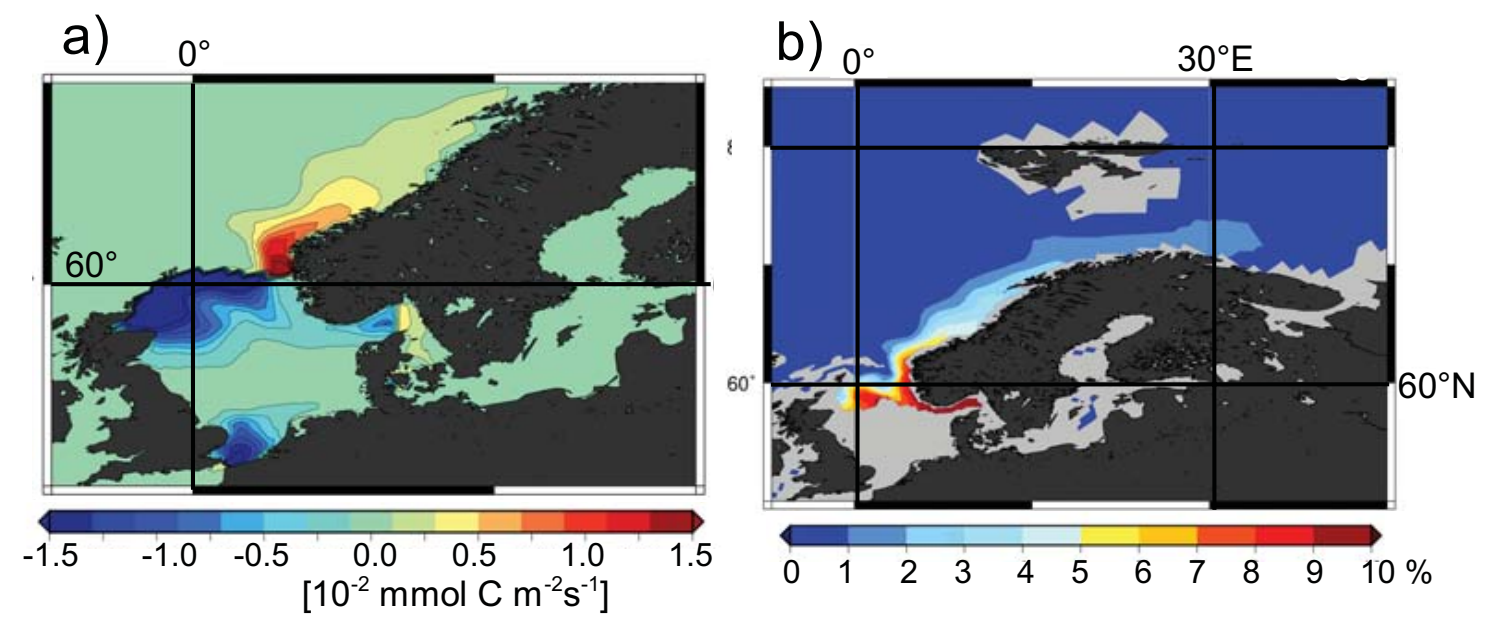

Fig. 9. (a) Sea-air carbon flux in experiment $\mathrm{CO}_{2}$-NS. A $10 \mathrm{yr}$ average of 1990-1999 is shown. Positive flux indicates degassing. (b) Relative change of dissolved inorganic carbon at $95 \mathrm{~m}$ depth between experiments $\mathrm{CO}_{2}-\mathrm{NS}$ minus experiment $\mathrm{CWE}$. Positive values indicate higher concentrations in experiment $\mathrm{CO}_{2}$-NS. An average over the years 1995-1999 is shown.

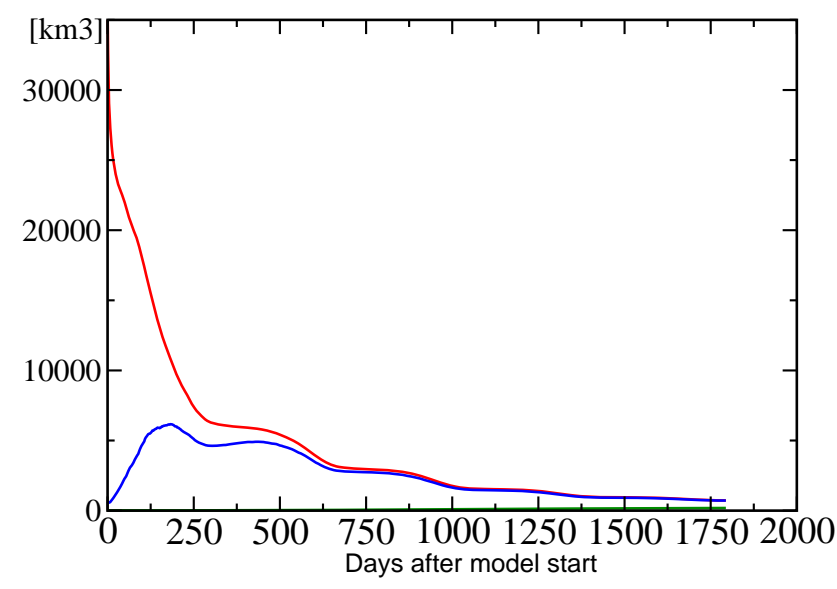

Fig. 10. Inventory of marked North Sea water in experiment MARKER. An average over all ensemble members is shown. The red line indicates the total ocean inventory. The blue line indicates open ocean inventory without the North Sea and green line indicates the deep ocean inventory below $1000 \mathrm{~m}$ water depth. The interensemble variability is very low compared to the mean signal.

model reproduces vertical mean gradients seen in observations in most cases. However, the variability is clearly underestimated. In the southern North Sea modelled mean values are too low.

The nutrient profiles reflect the stratified conditions with widespread depletion near the surface and high concentrations below the euphotic zone. Below the euphotic zone concentrations do not differ much from the winter situation (Fig. $5 \mathrm{fc}$, e). The model performs better for phosphate concentration. In case of nitrate it overestimates the concentrations in boxes 15, 23, 47, and 57. In the northernmost boxes nitrate concentrations fit well with observations.

\subsubsection{Overall performance}

We showed that the model reproduces fairly well the hydrographic and biogeochemical conditions before, during, and after the spring bloom. Thus, the main physical and biogeochemical processes, i.e. summer stratification, winter deep mixing and biological consumption, that are characteristic for the North Sea are sufficiently covered by the model especially in the northern North Sea, which is the key region for the exchange with the open NE Atlantic. Near the coasts the model bias for nitrate and salinity is larger, which is most likely related to the uncertainties in the prescribed river runoff calculated from the atmospheric forcing fields.

To roughly asses the overall model's performance we compare physical parameters and nutrients by means of root mean squared error, standard deviation and Pearson's correlation. These parameters are calculated using data from all 155 boxes. The results are summarized in Table 4 .

The model is able to represent the physical variables of the North Sea, either in terms of the bulk property (root mean square difference) and variability (correlation, and standard deviation). The correlation for nutrients is generally lower $(0.58 / 0.43)$ compared to temperature and salinity $(0.94 / 0.96)$. For temperature and salinity rms is far below the standard deviation of the corresponding observations. Nutrient rms lies roughly within the variability of observations. Hence, the model performs better for the physical parameters. But this is expected because in addition to the processes influencing salinity, i.e. precipitation, evaporation, advection, and diffusion, the nutrient distribution is strongly modulated by complex biological processes such as consumption, remineralization, etc. In conclusion the model represents the relevant physical and biogeochemical processes well enough to reproduce the seasonal characteristics of North Sea hydrography 

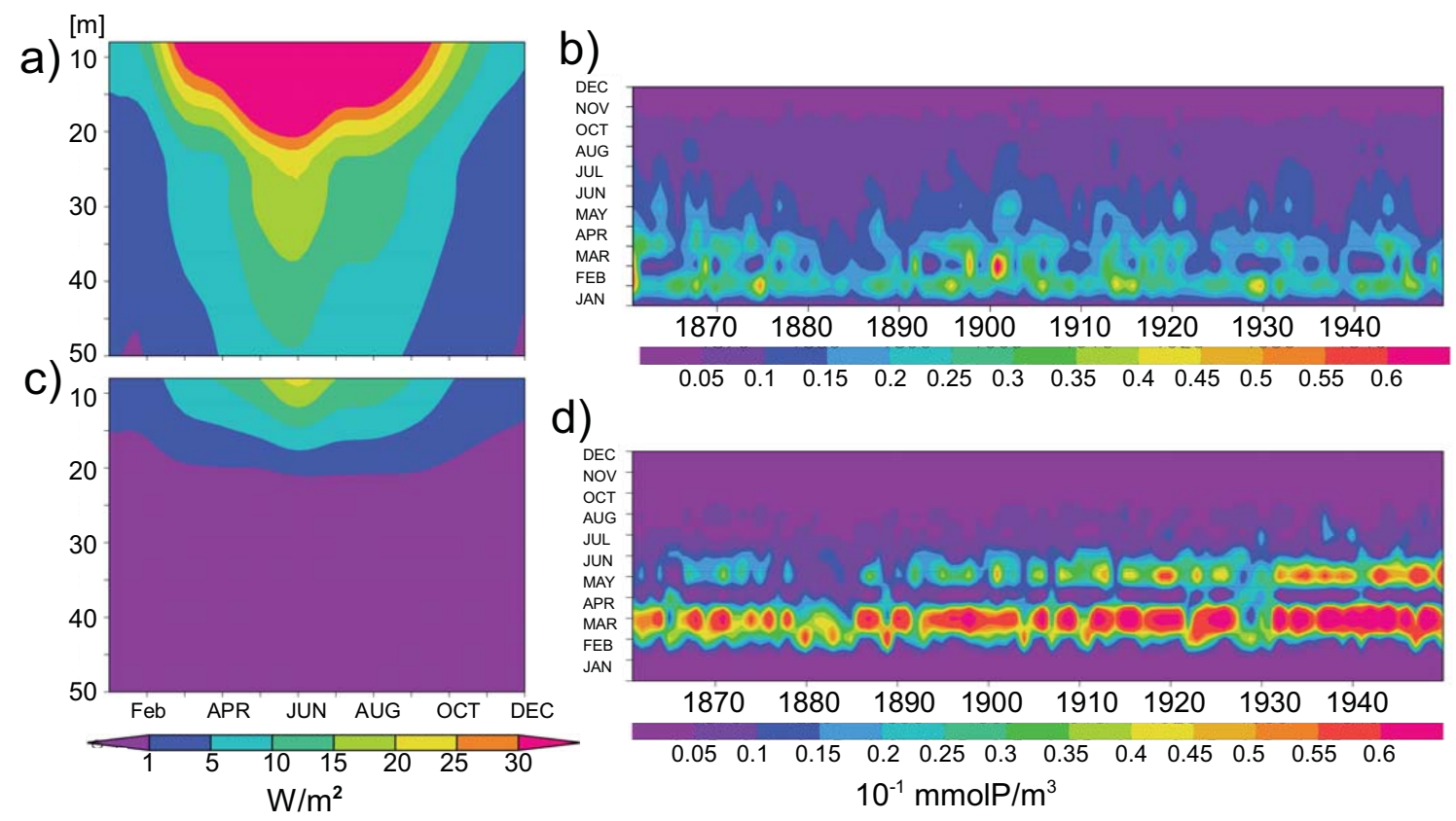

d)

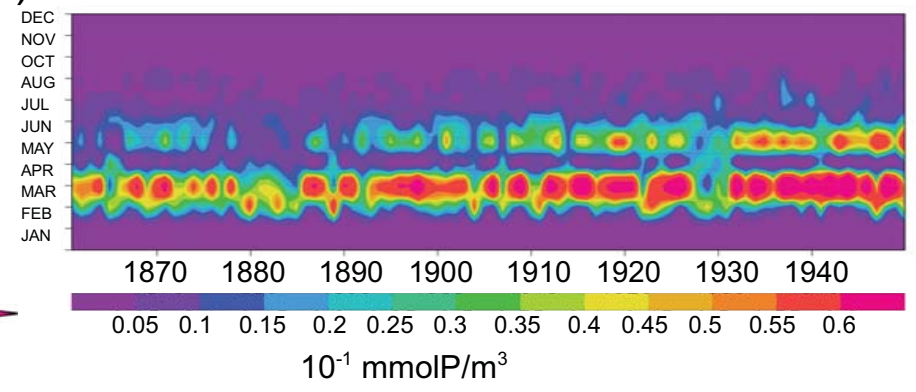

Fig. 11. (a) Available photosynthetic active short-wave radiation averaged over the North Sea south of $54^{\circ} \mathrm{N}$ using standard light scheme. (b) Seasonal cycles of phytoplankton (in $P$ units) concentration using standard light scheme. (c) and (d) same as (a) and (b) but using modified light scheme.

and biogeochemistry. Thus, we consider it to be adequate for addressing the questions on which this paper focuses.

\section{Climate change during the 21st century}

\subsection{Stratification on the shelf and along the shelf break}

The NW European shelf warms between $1.6 \mathrm{~K}$ in off-shore areas and $3.2 \mathrm{~K}$ near the coasts in response to the IPCC ARC4 A1B warming scenario. In the North Sea the annually averaged surface temperature increases by nearly $2 \mathrm{~K}$ in the course of the 21st century (Fig. 6a). This is somewhat lower than the model's global average warming of $2.5 \mathrm{~K}$. The atmospheric forcing is also marked by an intensifying hydrological cycle, which leads to enhanced moisture transports from the tropics to high latitudes. This intensification of the hydrological cycle is seen in most global warming scenarios (Allen and Ingram, 2002; Heldt and Soden, 2006; Mikolajewicz et al., 2007; Wentz et al., 2007). Thus, the global atmospheric pattern of evaporation minus precipitation is enhanced by increased surface fluxes. Due to this, most models predict a substantial freshening of the North Atlantic under climate warming. Additional evidence for an ongoing freshening has been/is also supported by observations (Durack et al., 2012). North of $40^{\circ} \mathrm{N}$ the entire Atlantic freshens considerably in our simulation (not shown). The North Sea as a shelf basin which is widely surrounded by land is also strongly affected by continental runoff. The enhanced river runoff results in a considerably stronger freshening in comparison with the open Atlantic and the sea surface salinity decreases by 0.75 in the North Sea (Fig. 6a) at the end of the 21st century. The freshening of the bottom layer is weaker than at the surface since the North Sea still receives saltier waters from the adjacent North Atlantic. Accordingly, the bottom to surface salinity difference increases by 0.1 (or $25 \%$ ) (Fig. 6b) in the course of the 21 st century. The shelf, thus, undergoes considerably enhanced stratification.

The stratification is accompanied by a strong decline of nutrient transports from the Atlantic into the North Sea during the second half of the 21 st century (Fig. $6 \mathrm{~g}, \mathrm{~h}$ ). The nutrient supply take places mainly during winter when vertical mixing is strongest throughout the year and nutrients are not consumed by biological activity due to limitation of biological production by light. In all climate change experiments the transport of dissolved phosphate and nitrate at the northern boundary of the North Sea is nearly halved (Fig. 6g, h) compared to preindustrial levels.

The decline in winter nutrient supply in the second half of the 21 st century (Fig. $6 \mathrm{~g}, \mathrm{~h}$ ) is not caused by a weaker inflow of Atlantic water masses northeast of Scotland. Instead, Atlantic water masses entering the North Sea have lower nutrient concentrations compared to the 20th century. This nutrient depletion is caused by weaker vertical mixing along the shelf break and the continental slope which, in turn, is caused by hydrographic changes.

To illustrate the changes in winter hydrography along the continental slope we show area-averaged profiles for the regions indicated by the red and green boxes shown in Fig. 7a. 
Northeast of the North Sea the surface waters become fresher and warmer (red box in Fig. 7b). The surface freshening is seen in the entire Atlantic north of $40^{\circ} \mathrm{N}$ (not shown). Further south, in the subtropics (not shown), salinities show overall positive anomalies in the upper few hundred metres. Because of this, subsurface waters from the subtropics, which are advected northward via the North Atlantic drift, become warmer and saltier, which causes higher salinities and temperatures at a depth of approximately $500 \mathrm{~m}$ in the region indicated by the red box (Fig. 7b). The changes in salinity and temperature result in an enhanced vertical density gradient within the upper 1000 metres (red box in Fig. 7b). The layer to layer gradients of potential density are overall increased in the upper $1000 \mathrm{~m}$ (Fig. 7b, lower panel middle plot) which weakens effectively the upward volume transport (Fig. 7b, lower panel left hand) which, in turn, lowers nutrient concentrations in the euphotic zone (Fig. 7b, lower panel right hand).

Directly north of the North Sea (green box) the hydrographic changes in the surface properties are similar to those described for the red box (Fig. 7c). The pycnocline at around $600 \mathrm{~m}$ strengthens. The profound decline in surface nutrient concentrations cannot be directly attributed to changes in the mean upward transport at deeper levels. As for this region upward and downward transports are roughly balanced in the upper $500 \mathrm{~m}$, we have to note that the gross up- and downward transports do not change as well at the end of the 21 st century. However, between 100 and $400 \mathrm{~m}$ the turbulent vertical mixing (not shown) is nearly halved, which indicates a weakening of tidally induced mixing. Of course, part of the nutrient depletion is advected from the adjacent NE Atlantic which is affected by a widespread thinning of the mixed layer (Fig. 8a, b).

The temporal evolution of hydrographic changes is shown in (Fig. 6c, d). Here we compare the upper $100 \mathrm{~m}$ of the water column with water from intermediate depth between 810 and $1060 \mathrm{~m}$. For the red box the upper $100 \mathrm{~m}$ of the Atlantic has warmed by $1.5 \mathrm{~K}$ and freshened by 0.25 per mille at the end of the 21 st century, whereas at intermediate depths only slight changes of temperature and salinity are seen (Fig. 6c, d). As a result of this enhanced stability of the water column, the mixing along the shelf break and in the neighbouring NE Atlantic reduces. Accordingly, the winter mixed-layer depth shallows by up to several hundred metres along the shelf break (Fig. 8a, b). As a result, the upward mixing of nutrient-rich waters from below the photic zone to shallower water depths is essentially reduced. These wide areas of the NW European shelf have been virtually cut off from the mid-depth Atlantic nutrient source. As a result, the on-shelf nutrient supply from the Atlantic breaks down and the nutrient inventory of the North Sea diminishes. In the northern North Sea the nutrient concentrations are lowered locally by up to $50 \%$ compared to the end of the 20th century (Fig. 8c, d), which has widespread negative effect on primary production (Fig. 8e, f). The lowered nutrient concen- trations are clearly the result of lowered imports from the NE Atlantic because no significant changes in the winter mixedlayer depth are seen in the North Sea. The southern North Sea is less affected as the nutrient-rich water masses from the north are usually diverted eastward when they reach the central North Sea. Here, nutrient concentrations are reduced due to the prescribed strong reduction of riverine phosphate inputs in the early 1990s.

\subsection{Decline in biological productivity}

Due to the reduced winter nutrient import from the Atlantic, which is caused by the stronger stratification, the nutrient inventory of the North Sea diminishes by $33 \%$ at the end of the 21 st century in the experiments without anthropogenic eutrophication, CWE and CWE-CEE. This results in lower biological production in the North Sea, which is reduced by $\sim 31 \%$ in experiments CWE and CWE-CEE from the last two decades of the 20th century to end of the 21st century (Fig. 6e, Table 2). The reduction of North Sea productivity is of similar magnitude as for the entire NW European shelf, where the reduction varies between 30 and $39 \%$ in the respective experiments (Table 2). Remarkably, the productivity decline on the shelf is much stronger than in the open ocean. For the open North Atlantic and the global ocean our model predicts a productivity reduction of only 17 and $15 \%$, respectively, which agrees well with results from other models which predict reductions between 2 and $20 \%$ resulting from stronger open ocean stratification (Steinacher et al., 2010). We thus conclude that the NW European shelf productivity is much more vulnerable to climate warming than the open ocean in our model. The higher vulnerability arises from the above described stratification feedback along the shelf which acts in addition to the well-known stratification impact on marine productivity in the open ocean (Steinacher et al., 2010). Due to the area-wide nutrient depletion, production lowers likewise in the adjacent NE Atlantic (Fig. 8e, f). Enhanced production is seen only in regions suffering from reduced sea ice coverage, which promotes a longer growing season. However this effect becomes important only in the Arctic Ocean where productivity increases substantially.

In experiment CWE-CEE-AES the evolution of production is strongly modified by the prescribed anthropogenic eutrophication. In the course of the 20th century the riverine nutrient discharges from industrial agriculture and detergents strongly increased (Paetsch and Lenhart, 2004) and stimulated productivity. Between 1975 and 1985, when prescribed discharges were highest, biological production in the North Sea was enhanced by $38.5 \%$ compared to the simulations CWE-CEE and CWE without this effect (Fig. 6e). The anthropogenically enhanced productivity is mainly restricted to the coastal regions of the southern and southeastern North Sea. In the early 1990s, the prescribed anthropogenic riverine nutrient input strongly declined, which explains the large drop in productivity at the end of the 20th 
century in experiment CWE-CEE-AES. In this experiment the stratification feedback along the shelf edge leads to a decline of North Sea productivity in the course of the 21st century as well (Fig. 6e). Here, uncertainties are associated with the chosen scenario for 21 st century nutrient discharges.

\subsection{Impact of rising $p \mathrm{CO}-2$ and declining productivity on carbon absorption}

Consistent with many studies based on observations (e.g. Frankignoulle and Borges, 2001; Thomas et al., 2005) our simulations show that the North Sea is a sink for atmospheric $\mathrm{CO}_{2}$. The yearly integrated carbon absorption varied between 9.3 and 11.8 million tons of carbon $(\mathrm{MtC}$, hereafter) in the last two decades of the 20th century (Table 2) in agreement with published values based on observations (9.5 Mt C, Thomas et al., 2005). Interestingly, the rising atmospheric $p \mathrm{CO}_{2}$ in experiment CWE-CEE has nearly no effect on carbon absorption in the North Sea (Fig. 6f, blue line). In this experiment carbon absorption is hardly higher than in experiment CWE without rising atmospheric $p \mathrm{CO}_{2}$. As the air-sea exchange for $\mathrm{CO}_{2}$ can be characterized - including the buffering of the carbonate system - by a piston velocity of $100 \mathrm{myr}^{-1}$, the North Sea is almost in equilibrium with rising atmospheric levels of $\mathrm{CO}_{2}$. In experiment CWE-CEE carbon absorption in the last two decades of the 20 th century is higher only by $0.59 \mathrm{MtC}(=6.3 \%)$ than in experiment CWE (Table 2) although the atmospheric $p \mathrm{CO}_{2}$ has risen by $22 \%$. At the end of the integrations carbon absorption in experiment CWE is even higher than in CWECEE although the atmospheric $p \mathrm{CO}_{2}$ was kept fixed at the preindustrial level in run CWE. In all experiments, the Atlantic water masses entering the North Sea decrease in DIC because the rising water temperatures lower the solubility of $\mathrm{CO}_{2}$ and enhanced stratification reduces the upward mixing of DIC-rich water masses from the deep Atlantic. This lowers the DIC imports from the Atlantic which, in turn, will lower the local water $p \mathrm{CO}_{2}$ in the North Sea and thus enhance carbon absorption. In experiments CWE-CEE and CWE-CEEAES, however, the DIC decrease in the adjacent Atlantic is relatively small compared to experiment CEE as the upperocean $p \mathrm{CO}_{2}$ in the former two experiments adapts rapidly to the rising atmospheric $p \mathrm{CO}_{2}$.

Changes in biological productivity have a stronger impact on carbon absorption of the North Sea than the rising atmospheric $p \mathrm{CO}_{2}$. Thus, in experiment CWE-CEE-AES absorption is enhanced by about $25 \%$ between 1975 and 1985 compared to run CWE-CEE (Fig. 6f). In all experiments the decreasing biological productivity in the course of the 21 st century strongly reduces atmospheric carbon absorption (Fig. 6f). The relative reductions in carbon absorption range between 23 and $37 \%$ for the North Sea and 12 and $32 \%$ for the entire NW European shelf (Table 2). The strongest decline is simulated in experiment CWE-CEE-AES (37\% in the North Sea) which likewise exhibits the strongest de- cline in productivity. Part of this decrease is a direct consequence of the assumed reduction in anthropogenic eutrophication. However, in the experiment CWE-CEE without anthropogenic nutrient input, the net uptake of anthropogenic $\mathrm{CO}_{2}$ is still reduced by $34 \%$.

\section{Does continental shelf pumping really enhance the oceanic storage of carbon?}

Strong absorption on the shelf does not necessarily result in long-term oceanic carbon sequestration since a large portion of the shelf water exported to the open ocean remains within the mixed layer and does not reach the deep ocean. In the following we describe two experiments that were designed to estimate how much anthropogenic carbon absorbed in the North Sea has the potential for long-term sequestration.

\subsection{Experiment $\mathrm{CO}_{2}-\mathrm{NS}$}

In experiment $\mathrm{CO}_{2}-\mathrm{NS}$ we repeated the period $1980-2000$ from experiment CWE (Table 1) but fixed the atmospheric $p \mathrm{CO}_{2}$ to $1112 \mathrm{ppm}$ over the North Sea whereas for the rest of the ocean the atmospheric $p \mathrm{CO}_{2}$ is as in experiment CWE (Table 1). As expected, experiment $\mathrm{CO}_{2}-\mathrm{NS}$ is marked by immediately high carbon fluxes into the North Sea in response to the sudden increase of atmospheric $p \mathrm{CO}_{2}$. After the initial adaptation period of about 2 months only those areas are marked by strong carbon absorption where low $p \mathrm{CO}_{2}$ waters from outside enter the North Sea (Fig. 9a) like in the English Channel and east of Scotland. Waters leaving the North Sea via the Norwegian coastal current are marked by vigorous degassing. Along the pathway of North Sea water a plume of pronounced DIC enrichment is visible (Fig. 9b). Most of this water enters the Barents Sea via the Norwegian Current at a core depth of around $100 \mathrm{~m}$. There is no significant portion that reaches directly the deep convection sites in the Greenland Sea.

Already after $20 \mathrm{yr}$ of integration the air-sea carbon fluxes are in equilibrium and show no significant trend in experiment $\mathrm{CO}_{2}$-NS. In experiment $\mathrm{CO}_{2}$-NS the North Sea still absorbs $6.03 \mathrm{MtCmonth}^{-1}$ more compared to experiment CWE. If all of the carbon absorbed over the North Sea would be sequestered in the deep open ocean, then the globally integrated oceanic carbon uptake should be enhanced by the same amount.

However, the global ocean uptake rises by only 1.2 $\mathrm{MtC}$ month $^{-1}$ along the Norwegian Current (Fig. 9a). This means that only $19.9 \%$ of the anthropogenic carbon absorbed in the North Sea has the potential for longer-term sequestration in the open ocean. The first-order effect of higher absorption over the North Sea is thus enhanced degassing in the open Atlantic. The efficiency of shelf carbon pumping is thus very low. Moreover, we repeated this experiment but simulated the period 2080-2100 instead of 1980-2000 
to find out whether or not the carbon shelf pumping is also very vulnerable to the climate warming in the course of the 21 st century. From this experiment we calculate that at the end of the 21 st century only $13.6 \%$ of carbon absorbed over the North Sea is being stored longer in the open ocean. This means that the efficiency of carbon shelf pumping is also decreasing in case of climate warming.

\subsection{Experiment MARKER}

In order to explain the mechanism behind the low efficiency of the carbon shelf pump, we carried out experiment MARKER (Table 1). This experiment was designed to quantify the amount of North Sea water that reaches the open ocean without undergoing intense modification by airsea gas exchange. For this, we marked the North Sea water stock with an artificial tracer (see Sect. 3) and integrated the model for four years. From the resulting tracer distribution we calculated the volume of water originating from the North Sea in the open ocean. We note that the uniform initialization of the tracers in the North Sea in this experiment differs from realistic conditions, since tracers (such as, e.g. DIC) are usually higher concentrated below the pycnocline during summer. Hence, the cross-pycnocline gradients in the northern North Sea are likely a bit too low during the first few weeks of the experiment. However, since the adaption time of the water layers above the pycnocline to the atmospheric boundary layer due to air-sea gas exchange is much faster than the turbulent mixing across the pycnocline in the water column, we do not believe this has significant influence on the calculated tracer export to the open ocean.

The results of experiment MARKER show that already within the first year the marked North Sea water stock is reduced to less than $15 \%$ of the initial volume of $37494 \mathrm{~km}^{3}$ (Fig. 10, red line). After this steep decline the marked North Sea water stock is further reduced at low rates between 2 and $3 \mathrm{~km}^{3} \mathrm{~d}^{-1}$. With the beginning of the next cold season (after abount 500 days of integration) the mixed layer thickens again which results in slightly enhanced decomposition rates in the range of 10 to $15 \mathrm{~km}^{3} \mathrm{~d}^{-1}$. After four years a stock of only $955 \mathrm{~km}^{3}$ (2.6\% of the initial stock) exists which is decomposed at rates between $0.2 \mathrm{~km}^{3} \mathrm{~d}^{-1}$ in summer and $0.7 \mathrm{~km}^{3} \mathrm{~d}^{-1}$ in winter. About $98 \%$ of this stock is located outside the North Sea in the open ocean (Fig. 10c, blue line). However, at the end of experiment MARKER only $188 \mathrm{~km}^{3}$ are stored at depths below $1000 \mathrm{~m}$ (Fig. 10, green line) though this stock still is slightly growing at a rate of approximately $0.1 \mathrm{~km}^{3} \mathrm{yr}^{-1}$. In conclusion, the rapid decomposition of the North Sea stock as well as the very low amount of North Sea water stored at depths below $1000 \mathrm{~m}$ clearly indicates that most of the water exported from the North Sea remains in the ocean's mixed layer, where it is still exposed to the atmosphere.

\section{Discussion of model results and potential uncertainties}

Since our biogeochemistry model was originally designed for the open ocean, it includes some simplifications compared to regional models and may lack important processes which may become important for biological production in the shelf environment. This imposes some uncertainties on the model's results on productivity and carbon absorption. In the following, we address the uncertainties associated with the model and experimental set-up.

\subsection{Biological production}

Our model predicts a substantial weakening of primary production and carbon absorption for the NW European shelf. These changes are caused by a widespread thinning of the mixed layer along the shelfbreak and the adjacent continental slope in the NE Atlantic which diminishes the on-shelf nutrient transport. This raises two questions: how robust are the results with regard to the fact that we have used only one specific warming scenario and forced our model with the output from only one atmospheric model? To address these questions we evaluated the response of the North Atlantic mixed layer in available scenario simulations carried out in the frame of the Max Planck Institute's contribution to the Climate Model Intercomparison Project (CMIP5). In particular we compare the historical experiments for the 20th century with the representative concentration pathway (RCP) warming scenarios 4.5 and 8.5. All model runs were conducted using the state of the art coupled atmosphere-ocean GCM ECHAM6/MPIOM/HAMOCC (MPI-ESM) with two different model resolutions (Jungclaus et al., 2013). The scenarios were carried out in ensembles of respectively three realizations, each of them initialized from three different restart files of the preindustrial control run (see Giorgetta et al., 2013 for details).

In all these scenarios we see a substantial shallowing of the ocean's mixed layer depth in the North Atlantic north of $40^{\circ} \mathrm{N}$. Although none of these model set-ups resolves the North Sea satisfactoryly, we note that there is a strong shallowing of the mixed layer around the north of Scotland especially along the Scotland-Faroer channel from which waters enter the North Sea. Hence, from these ensemble simulations we can conclude that the mixed layer thinning appears to be a robust feature throughout the different versions of the MPI-ESM and throughout the different warming scenarios. Moreover, we note that the mixed layer thinning is stronger in the high emission scenario RCP 8.5 compared to the moderate scenario RCP 4.5 . It is very likely that the mixed layer thinning in these simulations is also associated with a stronger stratification as this is the case in this study. Additional evidence for a likely shallowing of the North Atlantic mixed layer depth is derived from a multi-model study according to the SRES A2 scenario (Steinacher et al., 2010). 
Indeed, all four state-of-the-art coupled atmosphere-oceanecosystem models applied in this study showed the characteristic increase in stratification together with a profound decline in productivity. From this we conclude that the stratification feedback is not a phenomenon specific only to our model, but is a rather characteristic feature of warming scenarios seen in most coupled climate models.

Our finding of reduced on-shelf nutrient transports is in good agreement with recent modelling results of Holt et al. (2012) who found a reduction of nitrogen transports onto the NW European shelf by $20 \%$ at the end of the 21 st century. However, in their model they found only a small effect on primary production which decreased by only $5 \%$ on average. In fact the authors found several temperature related effects stimulating production. However, the temperature effect on biological production is very complex as it influences a number of biological processes with opposing effects on production such as the remineralization of organic matter, the growth and mortality rates of phytoplankton and zooplankton, etc. Therefore the response of biological production to elevated temperatures is subject to considerable uncertainty. We note that our model's organic matter remineralization is not temperature dependent, and thus it lacks the potential positive effect of enhanced nutrient recycling on biological production. Therefore, the strong decline in production predicted by our model may be slightly overestimated.

\subsection{Carbon absorption and shelf pumping}

Our results agree with observational and modelling studies indicating the NW European shelf and the North Sea in particular a net sink for atmospheric carbon (e.g. Frankignoulle et al., 2001; Bozec et al., 2005; Thomas et al., 2005; Borges et al., 2006; Prowe et al., 2009; Kühn et al., 2010' Lorkowski et al., 2012). Based on extensive observational campaigns in the North Sea Thomas et al. (2004) could show that much of the carbon absorbed reaches the open NE Atlantic. This agrees with tracer experiments indicating that $40 \%$ of carbon sequestered in the North Sea is exported to the NE Atlantic (Holt et al., 2009). However, only about 50\% of this are injected at below the pycnocline (Wakelin, et al., 2012) yielding an efficiency for the carbon shelf pump of $20 \%$. This agrees very well with our estimation of likewise $20 \%$ efficiency. In our model, much of the carbon exported to the open ocean through the Norwegian trench gets exposed to the atmosphere when it joins the Norwegian Current north of $60^{\circ} \mathrm{N}$ (Fig. 9). Here, the water column's stabilizing influence of the fresher surface waters originating from the Baltic Sea, which predominates along the Norwegian coast to the North Sea, gradually ceases due to mixing with higher saline Atlantic waters within the Norwegian Current. This region is not included in most regional model set-ups (e.g. Prowe et al.; 2009, Holt et al., 2012; Wakelin et al., 2012; Lorkowski et al., 2012). The region directly north of the North Sea is of minor importance in this respect.
An early attempt to asses the efficiency of the carbon shelf pump was undertaken by Yool and Fasham (2001). The authors used a global physical ocean GCM and implemented DIC and dissolved organic carbon (DOC) as passive tracers. Using a simple piston velocity for air-sea gas exchange they found the North Sea carbon pump to be $30 \%$ efficient, which is somewhat higher than estimated by Wakelin et al. (2012) and our study. Within the world's shelf area the North Sea efficiency appears low (ranked as 25 out of 32 shelf seas in Yool and Fasham, 2001). On the other hand, the strength of shelf pump is not only determined by its efficiency to export carbon to subpycnocline depths but also by the uptake of atmospheric carbon which is on the NW European shelf largely driven by biological processes (e.g. Gypens et al., 2004; Huthnance et al., 2009; Lorkowski et al., 2012).

\section{Summary and conclusions}

Here we have shown results from a novel approach to simulate biogeochemical changes on the NW European shelf with a global model with enhanced resolution on the NW European shelf. This approach avoids the problem of prescribing boundary conditions in the interior of the ocean for dynamical downscaling simulations of anthropogenic climate change.

Most global models (Steinacher et al., 2010) predict a decrease between 2 and $20 \%$ in open ocean productivity in response to climate warming. We have shown that on the NW European shelf the relative reduction in productivity is much stronger due to the suppression of lateral nutrient input resulting from the weakening of vertical mixing along the shelf break. This process is essential for both the nutrient supply to the outer shelf and productivity, and can be considered as most vulnerable under climate warming. In case of the North Sea the nutrient transport from the deep Atlantic declines by up to $\sim 50 \%$ in the 21 st century and productivity decreases by $\sim 35 \%$ assuming current rates of anthropogenic nutrient eutrophication. Even if we neglect anthropogenic eutrophication in our simulations (experiments CWE and CEE) the shelf productivity is reduced by about $\sim 30 \%$ in the North Sea and on the entire NW European shelf (Table 2). This is twice as strong as the reduction in open ocean productivity.

A decline of North Atlantic primary production over the last century has been already reported by Boyce et al. (2010). Shelf productivity has been assumed to be stable or rather to increase with an intensification of river runoff (Boyce et al., 2010), thus providing rather stable conditions for the ecological food web and for fisheries. This study provides a first hint that also the on-shelf ecological food web could be threatened by global warming. However, more modelling efforts involving a broader range of tested scenarios and atmospheric models are necessary.

Due to the declining biological production during the 21st century, the absorption of carbon dioxide in the North Sea 
(on the NW European shelf) likewise is reduced by $34 \%$ $(21 \%)$ or $37 \%(32 \%)$ when anthropogenic eutrophication is considered in the simulations.

This study supports observational evidence that the NW European shelf is an active sink for atmospheric $\mathrm{CO}_{2}$ (e.g. Frankignoulle and Borges, 2001). However, our results do not support the hypothesis that this leads to a substantially enhanced open ocean storage due to shelf sea pumping as proposed by Thomas et al. (2004). Water tracer experiments clearly indicate that most of the carbon dioxide absorbed on the shelf is not removed permanently from the atmosphere because most of the shelf water does not reach the deep ocean but remains within the ocean's mixed layer where it is still exposed to the air-sea gas exchange. We estimate that only $\sim 20 \%$ of the carbon absorbed in the North Sea contributes to the long-term oceanic carbon uptake. This fraction will be further reduced as a consequence of anthropogenic climate change.

\section{Appendix A}

\section{Light extinction scheme}

A pronounced feature of the North Sea is the strong seasonal cycle of nutrient concentration and primary production. During winter, photosynthesis and phytoplankton growth are strongly limited by light resulting in lower productivity and higher nutrient concentrations compared to summer when primary production is limited by nutrients due to strong stratification. In spring increasing short-wave radiation stimulates the characteristic spring phytoplankton bloom in the North Sea (e.g. Moll, 1998). Light intensity in the water column is further reduced due to absorption and scattering. Hence, for a realistic simulation of the timing and intensity of the spring bloom, a proper and physically consistent formulation of light penetration into the water column is necessary.

We therefore had to adopt a more elaborated scheme for light penetration that considers the variation of light intensity within individual grid cells. In Maier-Reimer et al. (2005) it was assumed that the light reaching the top of a box be effective over the whole box. For the open ocean this turned out to be a tolerable approximation. For our present model configuration with large regions of shallow water and the increased thickness of the surface layer it turned out to be no longer acceptable. As the mixing transport of light-absorbing particles to depth is blocked by the bottom, it favoured a substantial bloom in the southern North Sea already in February.

Light intensity is calculated from downward short-wave radiation at the surface $I(0)$ which is attenuated with depth $z$ by applying the attenuation coefficient atten in the following form:

$I(Z)=I(0) \times \exp (-$ atten $\times Z)$ because atten is variable to changing concentrations of chlorophyll in space and time, in the standard version of HAMOCC Eq. A1 is discretized onto the vertical $z(k)$ layers as

$I(k)=I(k-1) \times \exp (-\operatorname{atten} \times \mathrm{d} z(k-1))$,

hence, the light intensity at the top of the water column $i(0)$ is assumed for the entire layer thickness $z(1)$. Over the first $16 \mathrm{~m}$ of the surface layer no light attenuation is assumed. For clear waters in the open ocean this assumption has been proven to well-reproduce global fields of nutrients and primary production. Under the turbid conditions on shallow shelfs and near the coasts where high loads of suspended matter from rivers can reduce most of radiation already after a few metres this assumption is no longer realistic. As a consequence, the standard model simulates a first phytoplankton bloom already in early February in the southern North Sea (Fig. 11b), which is contrary to other studies (e.g. Moll, 1998; Paetsch and Kühn, 2008; Prowe et al., 2009).

For the present study we calculated an effective light intensity for all euphotic layers by integrating Eq. A1 in the following way:

$I_{\text {eff }}(k)=\frac{I(k-1)}{\text { atten } \times \mathrm{d} z(k)} \times(1-\exp (-\operatorname{atten} \times \mathrm{d} z(k)))$.

The second change we implemented refers to the fact that near the coasts light is attenuated additionally by resuspended silt due to vigorous tidal currents (Heath et al., 2002; Paetsch and Kühn, 2008). The process of resuspension follows the empirical approach for the North Sea as per Dobrynin (2009). The photosynthetic active radiation (PAR, Fig. 11) is then calculated as the sum of red and blue fractions and by expanding atten for the blue fraction according to

$$
\overbrace{\left.+(1-R) \exp \left(-z k_{\mathrm{w}}-k_{\mathrm{chl}} \int_{0}^{z} \operatorname{chl}\left(z^{\prime}\right) \mathrm{d} z^{\prime}-k_{\mathrm{s}} \int_{0}^{z} s\left(z^{\prime}\right) \mathrm{d} z^{\prime}\right)\right)}^{\text {ber }(z)=\operatorname{PAR}(0)(\overbrace{r \exp \left(-z k_{\mathrm{r}}\right)}^{\text {red fraction }}}
$$

with the attenuation coefficients for sea water scattering $k_{\mathrm{w}}=0.03 \mathrm{~m}^{-1}, \quad$ chlorophyll $\alpha$ $k_{\mathrm{chl}}=0.04\left(24.4 \mathrm{~g} \mathrm{chl} \mathrm{m}^{-3}\right)^{-1} \mathrm{~m}^{-1} \quad$ (where we adopted a relationship of 60 between phytoplankton-bound carbon and chlorophyll), and silt $k_{\mathrm{s}}=0.06\left(\mathrm{~g} \mathrm{~m}^{-3}\right)^{-1} \mathrm{~m}^{-1}$. The strongly attenuating red fraction $r=0.4$ is calculated using $k_{\mathrm{r}}=0.35 \mathrm{~m}^{-1}$.

The representation of the characteristic spring phytoplankton bloom substantially benefits from the improved light scheme (Fig. 11a, c). The unrealistically high light intensity of the standard light scheme forces a first phytoplankton bloom already in February (Fig. 11b). This is in strong 
contrast to observations which indicate that the main spring bloom occurs not before April (e.g. Moll, 1998). While the total productivity is nearly unchanged when using the improved light scheme instead of the standard scheme, the seasonal cycle is substantially improved.

\section{Supplementary material related to this article is

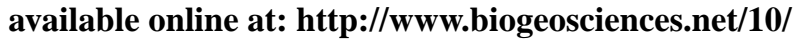 3767/2013/bg-10-3767-2013-supplement..zip.}

Acknowledgements. We thank Katharina Six for her intense revision of the manuscript which resulted in a significant improvement. Jason Holt contributed fruitful comments on the manuscript. The authors are also indebted to two unknown referees for their valuable comments and suggestions to clarify and improve the manuscript. Johannes Paetsch, Institute of Oceanography, University of Hamburg, provided daily loads of river nutrients between 1976 and 2006. This study was supported by the Federal Ministry of Education and Research, Germany, research grant 03f0443e AP3.1 (BMBF Nordatlantikprojekt II). Inga Hense, Institute of Hydrobiology and Fishery Science, University Hamburg, helped in the arguments about the consequences on fisheries. The authors would like to thank Fabian Große, Institut für Meereskunde, for his support in model validation.

The service charges for this open access publication have been covered by the Max Planck Society.

Edited by: C. Heinze

\section{References}

Adlandsvik, B.: Marine downscaling of a future climate scenario for the North Sea, Tellus, 60, 451-458, 2008.

Allen, M. R. and Ingram, W.J.: Constraints on future changes in climate and the hydrologic cycle, Nature, 419, 224, 2002.

Artioli, Y., Blackford, J. C., Butenschön, M., Holt, J. T., Wakelin, S. L., Thomas, H., Borges, A. V., and Allen, J. I.: The carbonate system in the North Sea: Sensitivity and model validation, J. Mar. Syst., 102-104, 1-13, 2012.

Beaugrand, G.: the North Sea regime shift: evidence, causes, mechanisms and consequences, Prog. Oceanogr., 60, 245-262, 2004.

Bergeron, J.-P. and Koueta, N.: Biological productivity enhancement over a continental shelf break (bay of biscay, NE Atlantic) evidenced by mesozooplankton aspartate transcarbamylase activity, J. Oceanogr., 67, 249-252, 2011.

Borges, A. V., Schiettecatte, L.-S., Abril, G., Delille, B., and Gazeau, F.: Carbon dioxide in european coastal waters, Estuarine Coastal Shelf Science, 70, 375-387, 2006.

Bozec, Y., Thomas, H., Elkalay, K., and de Baar, H. J. W.: The continental shelfpump for CO-2 in the North Sea - evidence from summer observation, Mar. Chem., 93, 131-147, 2005.

Broecker, W. S., and Peng, T.-H.: Tracers in the sea, eldigio press, palisades, New York, 690 pp, 1982.
Broecker, W. S.: The great ocean conveyor, Oceanography 4, 79-89, 1991.

Chassot, E., Bonhommeau, S., Dulvy, N. K., Melin, F., Watson, R., Gascuel, D., and le Pape, O.: Global marine primary production constrains fisheries catches, Ecol. Lett., 13, 495-505, doi:10.1111/j.1461-0248.2010.01443.x, 2010.

Chen, C.-T. A. and Borges, A. V.: Reconciling opposing views on carbon cycling in the coastal ocean: continental shelves as sinks and near-shore ecosystems as sources of atmospheric CO-2, Deep-Sea Res. Pt. II, 56, 578-590, 2009.

Dobrynin, M.: Investigating the dynamics of suspended particulate matter in the North Sea using a hydrodynamic transport model and satellite data assimilation, reports of the gkss research center, GKSS-Forschungszentrum Geesthacht GmbH, 12/2009, 93 pp., ISSN 0344-9629, 2009.

Durack, P. J., Wijffels, S. E., and Matear, R. J.: Ocean Salinities Reveal Strong Global Water Cycle Intensification During 1950 to 2000 , Science, 336, 455-458, doi:10.1126/science.1212222, 2012.

Eppley, R. W.: Temperature and phytoplankton growth in sea, Fish. Bull., 70, 1063-1085, 1972.

Food and Agriculture organization of the united nations: the state of world fisheries and aquaculture, Rome, ISSN 1020-5489, available at: http://www.fao.org/docrep/013/i1820e/i1820e.pdf, 2010.

Frankignoulle, M. and Borges, A.: European continental shelf a significant sink for atmospheric carbon dioxide, Global Biogeochem. Cy., 15, 560-576, 2001.

Friedland, K. D., Stock, C., Drinkwater, K. F., Link, J. S., Leaf, R. T., Shank, B. V., Rose, J. M., Pilskaln, C. H., Michael J., and Fogarty, M. J.: Pathways between primary production and fisheries yields of large marine ecosystems, Plos One 7, e28945, doi:10.1371/journal.pone.0028945, 2012.

Garcia, H. E., Locarnini, R. A., Boyer, T. P., Antonov, J. I., Zweng, M. M., Baranova, O. K., and Johnson, D. D.: World ocean atlas 2009, Vol. 4, nutrients (phosphate, nitrate, silicate), edited by: Levitus, S., NOAA Atlas nesdis 71, us government printing office, Washington, DC, 398 pp., 2010.

Giorgetta, M. A., Jungclaus, J. H., Reick, C. H., Legutke, S., Brovkin, V., Crueger, T., Esch, M., Fieg, K., Glushak, K., Gayler, V., Haak, H., Hollweg, H.-D., Ilyina, T., Kinne, S., Kornblueh, L., Matei, D., Mauritsen, T., Mikolajewicz, U., Mueller, W. A., Notz, D., Raddatz, T., Rast, S., Redler, R., Roeckner, E., Schmidt, H., Schnur, R., Segschneider, J., Six, K., Stockhause, M., Wegner, J., Widmann, H., Wieners, K.-H., Claussen, M., Marotzke, J., and Stevens, B: Climate change from 1850 to 2100 in MPI-ESM simulations for the Coupled Model Intercomparison Project 5, submitted, 2013.

Green, J. A. M., Simpson, J. H., Legg, S., and Palmer, M. R.: Internal waves, baroclinic energy fluxes and mixing at the European shelf edge, Cont. Shelf Res., 28, 937-950, doi:10.1016/j.csr.2008.01.014, 2008.

Gröger, M. and Mikolajewicz, U.: Note on the $\mathrm{CO}_{2}$ air-sea gas exchange at high temperatures, Ocean Model., 39, 284-290, doi:10.1016/j.ocemod.2011.05.003, 2011.

Große, F. and Moll, A.: Validation tool for analyzing vertical profile data of one state variable (valpro1var) by comparison of merged observational data sets and their preparation (obs_prep) - description and user guide, Technical Reports 01-2011, Institute of Oceanography, Hamburg, Germany, 83 pages, 2011. 
Gypens, N., Lancelot, C., and Borges, A. V.: Carbon dynamics and $\mathrm{CO}_{2}$ air-sea exchanges in the eutrophied coastal waters of the Southern Bight of the North Sea: a modelling study, Biogeosciences, 1, 147-157, doi:10.5194/bg-1-147-2004, 2004.

Heath, M. R., Edwards, A. C., Paetsch, J., and Turell, W. R.: Modelling the behaviour of nutrients in the coastal waters of Scotland, fisheries research services marine laboratory aberdeen, Scottish executive central research unit contract, 106 pp., 2002.

Heinze, C., Maier-Reimer, E., Winguth, A. M. E., and Archer, D.: A global oceanic sediment model for long term climate studies, Global Biogeochem. Cycles, 13, 221-250, 1999.

Heldt, I. M., and Soden, B. J.: Robust responses of the hydrological cycle to global warming, J. Clim. 19, 5686-5696, 2006.

Hibler, W. D.: A Dynamic Thermodynamic Sea Ice Model, J. Phys. Oceanogr., 9, 815-846, doi:10.1175/15200485(1979)009<0815:ADTSIM>2.0.CO;2, 1979.

Holt, J., Wakelin, S., and Huthnance, J.: Down-welling circulation of the northwest european continental shelf: a driving mechanism for the continental shelf carbon pump, Geophys. Res. Lett., 36, 114602, doi:10.1029/2009gl038997, 2009.

Holt, J., Wakelin, S, Lowe, J., and Tinker, J.: The potential impacts of climate change on the hydrography of the northwest european continental shelf, Prog. Oceanogr., 86, 361-379, 2010.

Huthnance, J. M., Holt, J. T., and Wakelin, S. L.: Deep ocean exchange with west-European shelf seas, Ocean Sci., 5, 621-634, doi:10.5194/os-5-621-2009, 2009.

Ilyina, T., Six, K., Segschneider, J., Maier-Reimer, E., Li, H., and Nunez-Riboni, I.: The global ocean biogeochemistry model HAMOCC: model architecture and performance as component of the mpi-earth system model in different cmip5 experimental realizations, J. Adv. Model. Earth Syst., doi:10.1002/jame.20017, accepted, 2013.

Joint, I., Wollast, R., Chou, L., Batten, S., Elskens, M., Edwards, E., Hirst, A., Burkill, P., Groom, S., Gibb, S., Miller, A., Hydes, D., Dehairs, F., Antia, A., Barlow, R., Rees, A., Pomroy, A., Brockmann, U., Cummings, D., Lampitt, R., Loijens, M., Mantoura, F., Miller, P., Raabe, T., Alvarez-Salgado, X., Stelfox, C., and Woolfenden, J.: Pelagic production at the Celtic Sea shelf break (1995), Deep-Sea Res. Pt. I, 48, 3049-3081, 2001.

Jungclaus, J., Keenlyside, N., Botzet, M., Haak, H, Luo, J.J., Latif, M. Marotzke, J., Mikolajewicz, U., and Roeckner, E.: Ocean circulation and tropical variability in the coupled model ECHAM5/mpi-om, J. Climate, 19, 3952-972, doi: http://dx.doi.org/10.1175/jcli3827.1, 2006.

Jungclaus, J. H., Fischer, N., Haak, H., Lohmann, K., Marotzke, J., Matei, D., Mikolajewicz, U., Notz, D., and von Storch, J.-S: Characteristics of the ocean simulations in mpiom, the ocean component of the MPI Earth System Model, J. Adv. Model. Earth Syst., doi:10.1002/jame.20023, 2013.

Kühn, W., Paetsch, J., Thomas, H., Borges, A. V., Schiettecatte, L. S., Bozec, Y., and Prowe, A. E. F.: Nitrogen and carbon cycling in the North Sea and exchange with the north Atlantic a model case study, part ii: carbon budget and fluxes, Cont. Shelf Res., 16, 1701-1716, 2010.

Kanzow, T., Cunningham, S. A., Johns, W. E., Hirschi, J. J.-M., Marotzke, J., Baringer, M. O., Meinen, C. S., Chidichimo, M. P., Atkinson, C., Beal, L. M., Bryden, H. L., and Collins, J.: Seasonal variability of the Atlantic meridional overturning circulation at $26.5^{\circ} \mathrm{N}$, J. Clim., 23, 5678-5698,
doi:10.1175/2010JCLI3389.1, 2010.

Lorkowski, I., Paetsch, J., Moll, A., and Kühn, W.: Interannual variability of carbon fluxes in the North Sea from 1970 to 2006 - comparing effects of abiotic and biotic drivers of the gasexchange of $\mathrm{Co}_{2}$, Esutar. Coast. Shelf S., 100, 38-57, 2012.

Marsland, S. J., Haak, H., Jungclaus, J. H., Latif, M., and Röske, F.: The max planck institute global ocean/sea-ice model with orthogonal curvilinear coordinates, pelagic production at the celtic sea shelf break (1995), Ocean Model., 5, 91-127, 2003.

Maier-Reimer, e.: geochemical cycles in an ocean general circulation model. preindustrial tracer distributions, Blobal Biogeochemical Cycles, 7, 645-677, 1993.

Maier-Reimer, E., Kriest, I., Segschneider, J., and Wetzel, P.: The hamburg ocean carbon cycle model hamocc 5.1 - technical description release 1.1, reports on earth system science, 14, 50 pp., available at: http://www.mpimet.mpg.de/fileadmin/ publikationen/erdsystem_14.pdf, 2005.

Meier, H.E.M, Hordoir, R., Andersson, H.C., Dieterich, C., Eilola, K., Gustafsson, B.G., Höglund, A., and Schimanke, S.: Modeling the combined impact of changing climate and changing nutrient loads on the Baltic sea environment in an ensemble of transient simuilation for 1961-2099, Climate Dynamics, 39, 2421-2441, doi:10.1007/s00382-012-1339-7

Meybeck, M. and Ragu, A.: River discharges to the oceans: an assessment of suspended solids, major ions and nutrients, unpublished report of the United Nations Environmental Programme, 1995.

Moll, A.: Regional distribution of primary production in the North Sea simulated by a three-dimensional model, J. Marine Syst., 16, 151-170, 1998.

Moll, A. and Radach, G.: Review of three-dimensional ecological modelling related to the North Sea shelf system, part 1: models and their results, Prog. Oceanogr., 57, 175-217, doi:10.1016/s0079-6611(03)00067-3, 2003.

Mikolajewicz, U., Gröger, M., Maier-Reimer, E., Schurgers, G. Vizcaino, M.: Long-term effects of anthropogenic $\mathrm{CO}_{2}$ emissions simulated with a complex earth system model, Clim. Dyn., 28, 599-633, doi:10.1007/s00382-006-0204-y, 2007.

New, A. L. and Pingree, R. D.: Evidence for internal tidal mixing near the shelf break in the bay of biscay, Deep-Sea Res., 37, 1783-1803, 1990.

Olbert, A., Hartnett, M., Dabrowski, T., and Mikolajewicz, U.: Long-term inter-annual variability of a cyclonic gyre in the western Irish Sea, Cont. Shelf Res., 31, 1343-1356, doi:10.1016/j.csr.2011.05.010, 2011.

Orr, J., Maier-Reimer, E., Mikolajewicz, U., Monfray, P., Sarmiento, J. L., Toggweiler, J. R., Taylor, N. K., Palmer, J., Gruber, N., Sabine, C.-L., le Quere, C., Key, R. M., and Boutin, J.: Estimates of anthropogenic carbon uptake from four 3-d global ocean models, Global Biogeochem. cy., 15, 43-60, 2001.

Pacanowski, R. C. and Philander, S. G. H.: Parameterization of vertical mixing in numerical models of tropical oceans, J. Phys. Oceanogr, 11, 1981.

Paetsch, J. and Kühn, W.: Nitrogen and carbon cycling in the North Sea and exchange with the north Atlantic - a model study. part i. nitrogen budget and fluxes, Cont. Shelf Res., 28, 767-787, 2008.

Paetsch, J. and Lenhart, H.-J.: Daily loads of nutrients, total alkalinity, dissolved inorganic carbon and dissolved organic carbon of the european continental rivers for the years 1977-2002, reports 
center for marine und climate research - Series b: Oceanography 2004, University of Hamburg, 2004.

Pauly, D., Christensen, V., Guenette, S., Pitcher, T. J., Rashid, T. U., Walters, C. J., Watson, R., and Zeller, D.: Towards sustainability in world fisheries, Nature, 418, 689-695, 2002.

Persechino, A., Mignot, J., Swingedouw, D., Labetoulle, S., and Guilyardi, E.: Decadal predictability of the Atlantic meridional overturning circulation and climate in the IPSL-CM5A-LR model, Clim. Dyn., doi:10.1007/s00382-012-1466-1, 2012.

Pingree, R. D. and Mardell, G. T.: Slope turbulence, internal waves, and phytoplankton growth at the celtic sea shelf break, Philos. T. R. Soc. Lond. a, 302, 663-682, 1981.

Prowe, A. E. F., Thomas, H., Paetsch, J., Kühn, W., Bozec, Y., Schiettecatte, L.-S., Borges, A. V., and de Baar, H. J. W.: Mechanisms controlling the air-sea $\mathrm{CO}_{2}$ flux in the North Sea, Cont. Shelf Res., 29, 1801-1808, 2009.

Radach, G., and Moll, A.: Review of three-dimensional ecological modelling related to the North Sea shelf system. Part II: Model validation and data needs, Oceanogr. Mar. Biol.: an Anual Review, 44, 1-60, 2006.

Raven, J. A. and Falkowski, P. G.: Oceanic sinks for atmospheric $\mathrm{CO}_{2}$, Plant Cell Environ., 2, 741-755, doi:10.1046/j.13653040.1999.00419.x, 1999.

Roeckner, E., Lautenschlager, M., and Esch, M.: IPCC-ar4 mpiECHAM5_t63131 mpi-om_gr1.5140, (pre-industrial control experiment): atmosphere 6 hour values mpimet/mad germany, World Data Center for Climate, Deutsches Klimarechenzentrum DKRZ GmbH, Hamburg, doi:10.1594/wdcc/eh5-t63131_omgr1.5140_ctl_6h, 2006.

Sein, D. V., Mikolajewicz, U., Gröger, M., Maier-Reimer, E., Fast, I., Jacob, D., and Hagemann, S.: Regionally coupled atmosphere -ocean -sea ice -marine biogeochemistry model REMO/MPIOM/HAMOCC. Downscaling of future climate change A1B scenario for the North Atlantic and North European shelves, in preparation, 2013.

Skogen, M.D., Drinkwater, K., Hjollo, S.S., and Schrumm, C.: North Sea sensitivity to atmospheric forcing, J. Mar. Syst., 78, 180-192, doi:10.1016/j.jmarsys.2009.06.001, 2011.

Steinacher, M., Joos, F., Frölicher, T. L., Bopp, L., Cadule, P., Cocco, V., Doney, S. C., Gehlen, M., Lindsay, K., Moore, J. K., Schneider, B., and Segschneider, J.: Projected 21 st century decrease in marine productivity: a multi-model analysis, Biogeosciences, 7, 979-1005, doi:10.5194/bg-7-979-2010, 2010.

Sweby, P. K.: High resolution schemes using flux limiters for hyperbolic conservation laws, Siam J. Numer. Anal., 21, 995-1011, 1984.

Taucher, J., and Oschlies, A.: Can we predict the direction of marine primary production change under global warming?, Geophys. Res. Lett., 38, 102603, doi:10.1029/2010g1045934, 2011.
Taylor, K. E.: Summerizing multiple aspects of model performance in a single diagram, J. Geophys. Res., 106, 7183-7192, 2001.

Thomas, H., Bozec, Y., Eelkalay, K., and de Baar, H. J. W.: Enhanced open ocean storage of $\mathrm{CO}-2$ from shelf sea pumping, Science, 304, 1005-1008, 2004.

Thomas, H., Bozec, Y., de Baar, H. J. W., Elkalay, K., Frankignoulle, M., Schiettecatte, L.-S., Kattner, G., and Borges, A. V.: The carbon budget of the North Sea, Biogeosciences, 2, 87-96, doi:10.5194/bg-2-87-2005, 2005.

Thomas, H.: The continental shelf pump hypothesis: a pilot study in the North Sea (canoba), shipboard report of the rv pelagia cruises 64pe184, 64pe187, 64pe190 and 64pe195, 63 pp., R. Neth. Inst. of Sea Res., Texel, Netherlands, 2002.

Thomas, M., Sündermann, J., and Maier-Reimer, E.: Consideration of ocean tides in an oGCM and impacts on subseasonal to decadal polar motion excitation, Geophys. Res. Lett., 28, 24572460, 2001.

Tsunogai, S., Watanabe, S., and Sato, T.: Is there a continental shelf pump for the absorption of atmospheric CO-2?, Tellus B, 51, 701-712, 1999.

Wakelin, S. L., Holt, J. T., Blackford, J. C., Allen, J. I., Butenschön, M., and Artioli, Y.: Modeling the carbon fluxes of the northwest european continental shelf: validation and budgets, J. Geophys. Res., 117, C05020, doi:10.1029/2011jc007402, 2012.

Wanninkhof, R.: Relationship between wind speed and gas exchange over the ocean, J. Geophys. Res., 97, 7373-7382, 1992.

Wentz, F. J., Ricciardulli, L., Hilburn, K., and Mears, C.: How Much More Rain Will Global Warming Bring?, Science, 317, 233-235, doi:10.1126/science.1140746, 2007.

Wetzel, P.: Interannual and decadal variability in the air-sea exchange of $\mathrm{CO}_{2}$ - a model study, reports on earth system science, 7, availble at: www.mpimet.mpg.de/fileadmin/ publikationen/erdsystem_07.pdf, 2004.

Wetzel, P., Winguth, A., and Maier-Reimer, E.: Sea to air CO-2 flux from 1948 to 2003, a model study, Global Biogeochem. Cy., 19, gb2005, doi:10.1029/2004gb002339, 2005.

Winther, N. G. and Johannessen, J. A.: North Sea circulation: Atlantic inflow and its destination, J. Geophys. Res., 111, c12018, doi:10.1029/2005jc003310, 2006.

Wollast, R.: Continental margin - review of geoachemical settings, in: ocean margin systems, edited by: Wefer, G., Billet, D., Hebbeln, D., Joergenson, B. B., Schlueter, M., and van Weering, T. C. E., Springer Verlag, Berlin Heidelberg New York, 1531, 1998.

Yool, A. and Fasham, J. R.: An examination of the "continental shelf pump" in an open ocean general circulation model, Global Biogeochem. Сy., 15, 831-844, 2001. 